\title{
Charakteristika sexuellen Missbrauchs durch katholische Geistliche \\ Zentrale Ergebnisse einer quantitativen Betroffenenbefragung
}

Deborah F. Hellmann, Lisa M. Dinkelborg, Gina R. Wollinger, Sandra Fernau

\section{Einleitung}

Der vorliegende Beitrag liefert einen Überblick über die zentralen empirischen Ergebnisse der Betroffenenbefragung des Kriminologischen Forschungsinstitut Niedersachsen (KFN) zu Umständen und Kontexten, in denen es zu sexuellem Missbrauch durch katholische Geistliche in Deutschland gekommen ist. Im Rahmen der Studie wurde eine Gruppe von Betroffenen befragt, die in ihrer Kindheit oder Jugend sexuelle Gewalt durch Vertreterinnen und Vertreter der katholischen Kirche erfahren hatten und sich an das KFN wandten, um dessen Forschungsbemühungen zu unterstützen.

Fragen, die dieses Kapitel zu beantworten versucht, betreffen die konkreten Hintergründe der Taten. Erstens sollten Informationen über die Betroffenen (z. B. Alter zum Zeitpunkt der ersten und letzten Viktimisierung) dargestellt werden, um die Frage beantworten zu können: „Wer waren die Betroffenen?" Ein zweites Ziel bestand darin, Details zu den spezifischen Charakteristika der Täterinnen und Täter (z. B. Anzahl, Alter, Beziehung zur Familie) zu erheben: „Wer waren die Täterinnen und Täter?“ Die dritte Leitfrage (,Was ist passiert?“) zielte darauf ab, das Missbrauchsgeschehen selbst näher zu beleuchten (z. B. Anbahnung der ersten Tat). Folglich geht es im vorliegenden Beitrag um die direkten Umstände des sexuellen Missbrauchs durch katholische Geistliche aus Sicht der Betroffenen. 


\section{Zentrale Ergebnisse zum sexuellen Missbrauch durch katho- lische Geistliche in der KFN-Befragung}

Bevor die zentralen Befunde der Befragung berichtet werden, geben wir einen kurzen Überblick über die Konzeption der Studie und die gewonnene Stichprobe (siehe auch Fernau \& Hellmann, 2014; Kap. 3 in diesem Band). Im Anschluss daran werden Informationen zu den Charakteristika der Betroffenen (II.1), den Täterinnen bzw. Tätern (II.2), sowie den spezifischen Delikten und den Kontexten der sexuellen Misshandlungen durch katholische Geistliche (II.3) und dessen Beendigung (II.4) dargestellt.

Von insgesamt 113 vollständig ausgefüllten Fragebögen, die Betroffene von sexuellem Missbrauch durch katholische Geistliche nach dem vorangegangenen Aufruf des KFN eingesandt hatten, konnten 104 für die dem vorliegenden Kapitel zugrunde liegenden Analysen ausgewertet werden. Es handelte sich bei der gewonnenen Stichprobe um $N=104$ Personen, die in ihrer Kindheit oder Jugend von einem bzw. mehreren katholischen Geistlichen sexuell missbraucht worden waren. Konkret werden hier unter dem Term „katholische Geistliche“ weibliche und männliche Ordensangehörige, Priester, Kapläne, Vikare, Diakone und Priesteramtsanwärter zusammengefasst (siehe Fernau \& Hellmann, 2014; Kap. 3 in diesem Band). In der ausgewerteten Stichprobe lag ein Altersdurchschnitt von $M=56.14$ Jahren vor $(S D=10.33) .{ }^{1}$ Die Altersspanne reichte von 34 bis 79 Jahren, wobei vor allem Personen mit einem Alter zwischen 50 und 69 Jahre vertreten waren. Auffällig war die Geschlechterverteilung innerhalb der Stichprobe: Auf den Aufruf des KFN meldeten sich $n=26$ (25.0\%) weibliche Betroffene. Die Anzahl der rekrutierten männlichen Betroffenen war somit dreimal höher $(74.0 \%, n=77$; fehlende Werte $1.0 \%, n=1)$.

1 Die Abkürzung $M$ steht für den Mittelwert (Durchschnitt, arithmetisches Mittel) aller Messwerte einer spezifischen Variable. In diesem Fall bezeichnet $M$ das durchschnittliche Alter aller Befragten. SD bedeutet Standardabweichung (Streuung) und berechnet sich aus der Wurzel der Varianz (Summe der quadrierten Abweichungen der Messwerte vom Mittelwert $M$ relativiert an der Anzahl aller Messwerte). Vereinfacht gesagt bildet die Standardabweichung die Unterschiedlichkeit der einzelnen Messwerte $a b$. 


\section{II.1 Wer waren die Betroffenen?}

Der folgende Abschnitt fokussiert neben dem Alter und Geschlecht der Betroffenen auch deren Lebensmittelpunkt zum Zeitpunkt der Missbrauchshandlung(en). Besonders thematisiert wird der institutionelle Kontext als Kontaktquelle der Delinquentinnen bzw. Delinquenten zu den Betroffenen. Die Ausführungen zu Kontaktmöglichkeiten zwischen den Täterinnen bzw. Tätern und den Betroffenen verdeutlichen weitere Situationen, in welchen es den Beschuldigten möglich war, die Betroffenen kennenzulernen.

Der sexuelle Missbrauch im kirchlichen Kontext weist in der Regel im Vergleich zu sexuellem Missbrauch außerhalb des kirchlichen bzw. institutionellen Kontexts die Besonderheit auf, dass Jungen häufiger betroffen sind als Mädchen (siehe z. B. Finkelhor, 1994; John Jay College, 2004; Lueger-Schuster, 2012; Pereda, Guilera, Forns \& Gómez-Benito, 2009; Stadler, Bieneck \& Pfeiffer, 2012; siehe auch Fernau, Treskow \& Stiller, 2014; Kap. 2 in diesem Band). Wie eingangs bereits erwähnt, befanden sich in der für das vorliegende Forschungsvorhaben rekrutierten Stichprobe ebenfalls deutlich mehr männliche als weibliche Betroffene. Da die Betroffenen selbstselektiv an der Befragung teilnahmen, kann dieses ungleiche Geschlechterverhältnis zwar nicht als repräsentativ für alle Missbrauchsfälle durch katholische Geistliche gelten. Gleichzeitig bestehen keine begründeten Annahmen dafür, dass von allen Betroffenen deutlich mehr männliche als weibliche dem Aufruf zur Teilnahme an der Studie gefolgt sind.

Zur kontextuellen Einordnung des sexuellen Missbrauchs wurde fokussiert, welche Charakteristika den Lebensmittelpunkt und den Wohnort der Betroffenen zum Tatzeitpunkt prägten. Dazu wurden die Betroffenen um Angaben zu ihrem Lebensmittelpunkt zur Zeit des Missbrauchs gebeten sowie zur geschätzten Größe und religiösen Ausrichtung des Ortes, in dem sie zum Zeitpunkt des Missbrauchs gelebt hatten (siehe Tabelle 1).

Die meisten Befragten lebten eigenen Angaben zufolge zum Zeitpunkt der sexuellen Gewalterfahrung bei den Eltern oder einem Elternteil (46.2\%). Mit $57.5 \%$ traf dies etwas häufiger auf weibliche (vs. männliche, $42.9 \%$ ) Betroffene zu. In einem Heim lebten zu der Zeit der Viktimisierungen ungefähr drei von zehn weiblichen bzw. männlichen Betroffenen. Als dritthäufigsten Lebensmittelpunkt zur Zeit des sexuellen Missbrauchs benannten die männlichen Betroffenen ein Internat (22.1 \%), wäh- 
rend lediglich $3.8 \%$ der weiblichen Betroffenen diese Antwortoption wählten. ${ }^{2}$

Tabelle 1. Angaben der Betroffenen zu ihrer Wohnsituation zum Zeitpunkt des Missbrauchs in gültigen Prozent $(N \geq 101)$

\begin{tabular}{|c|c|c|c|}
\hline & Gesamt & Weiblich & Männlich \\
\hline \multicolumn{4}{|l|}{ Lebensmittelpunkt } \\
\hline Bei den Eltern oder einem Elternteil & $46.2 \%$ & $57.5 \%$ & $42.9 \%$ \\
\hline Bei den Großeltern & $1.9 \%$ & $3.8 \%$ & $1.3 \%$ \\
\hline Bei Adoptiv- oder Pflegeeltern & $1.9 \%$ & - & $2.6 \%$ \\
\hline In einem Heim & $29.8 \%$ & $30.8 \%$ & $29.9 \%$ \\
\hline In einem Internat & $18.3 \%$ & $3.8 \%$ & $22.1 \%$ \\
\hline Sonstiges & $1.9 \%$ & $3.8 \%$ & $1.3 \%$ \\
\hline \multicolumn{4}{|l|}{ Einwohnerzahl } \\
\hline Bis zu $1999 \mathrm{EW}$ & $19.8 \%$ & $15.4 \%$ & $21.6 \%$ \\
\hline 2000 bis $4999 \mathrm{EW}$ & $18.8 \%$ & $11.5 \%$ & $20.3 \%$ \\
\hline 5000 bis $19999 \mathrm{EW}$ & $12.9 \%$ & $19.2 \%$ & $10.8 \%$ \\
\hline 20000 bis $49999 \mathrm{EW}$ & $11.9 \%$ & $11.5 \%$ & $12.2 \%$ \\
\hline 50000 bis $99999 \mathrm{EW}$ & $7.9 \%$ & $7.7 \%$ & $8.1 \%$ \\
\hline 100000 bis $499999 \mathrm{EW}$ & $14.9 \%$ & $19.2 \%$ & $13.5 \%$ \\
\hline 500000 und mehr EW & $7.9 \%$ & - & $10.8 \%$ \\
\hline Ich weiß es nicht. & $5.9 \%$ & $15.4 \%$ & $2.7 \%$ \\
\hline \multicolumn{4}{|l|}{ Anteil katholischer EW } \\
\hline EW mehrheitlich katholisch & $69.3 \%$ & $65.4 \%$ & $70.3 \%$ \\
\hline Ungefähr 50 \% der EW katholisch & $10.9 \%$ & $11.5 \%$ & $10.8 \%$ \\
\hline Katholische EW in der Minderheit & $19.8 \%$ & $19.2 \%$ & $18.9 \%$ \\
\hline
\end{tabular}

Anmerkungen. EW = Einwohnerinnen und Einwohner

Wenn im Folgenden von einem ,institutionellen Kontext" die Rede ist, in dem sich der sexuelle Missbrauch ereignet hatte, handelt es sich um solche

2 Um die Anonymität der Betroffenen zu wahren, werden die detaillierten Angaben in der Kategorie „Sonstiges“ (1.9\%) hier nicht weiter aufgeschlüsselt. 
Betroffenen, die berichteten, dass sie zum Zeitpunkt des Missbrauchs in einem Heim oder Internat gelebt hatten. Sicherlich sind Heim- und Internatsaufenthalte nicht in allen Belangen gleichzusetzen. Da zwischen den Angaben derjenigen Betroffenen, die zum Zeitpunkt des sexuellen Missbrauchs in einem Internat vs. Heim gelebt hatten, jedoch große Gemeinsamkeiten (z. B. Alter bei der letzten Viktimisierung) und nur wenige Unterschiede (z. B. Missbrauchsdauer) auftraten, wurde zusammenfassend die Oberkategorie ,institutioneller Kontext“" gewählt. Sofern sich spezifische Unterschiede zwischen Betroffenen mit Heim- vs. Internatsaufenthalt in ihrer Kindheit nachweisen ließen, wurden diese bei der Beschreibung der Ergebnisse explizit dargestellt.

Das gehäufte Vorkommen von Betroffenen sexuellen Missbrauchs aus Heimen und Internaten kann beispielsweise anhand des 4-FaktorenModells einer Straftat von Finkelhor (1984) erläutert werden. Finkelhor identifizierte neben der Motivation zur Straftat (z. B. Blockade intimer Beziehungen zu Erwachsenen) und der Überwindung internaler Hemmungen (z. B. Ausreden, Rechtfertigungen) vor allem die Überwindung externaler Hemmungen (Gelegenheit und Räume für den Missbrauch) und der Widerstandskraft des Kindes als zentrale Faktoren. Durch die besondere Lebens- und Betreuungssituation in Heimen und Internaten waren sowohl die Gelegenheiten vielzählig als auch die Widerstandskräfte der Kinder gemindert, da Kinder, die in Heimen aufwachsen, mit erhöhter Wahrscheinlichkeit ein starkes Bedürfnis nach Bindung (z. B. MacLean, 2003) und ein vermindertes Selbstwertgefühl (z. B. Youngleson, 1973) aufweisen.

Mehr als die Hälfte der Betroffenen (51.5\%) berichteten, zur Zeit des Missbrauchs in kleinen Städten mit bis zu 20000 Einwohnerinnen und Einwohnern gelebt zu haben. Ungefähr jede siebte betroffene Person lebte zum Missbrauchszeitpunkt in einer Großstadt mit einer Einwohnerzahl zwischen 100000 und 499999 und je $7.9 \%$ in einer Stadt mit 50000 bis 99999 oder mehr als 499999 Einwohnerinnen und Einwohnern (siehe Tabelle 1).

Die Gegenden, in denen sich diese Wohnorte befanden, waren nach Einschätzung der Betroffenen größtenteils von einer katholischen Bevölkerung dominiert (69.3\%). Nur in ungefähr einem Fünftel der Fälle bestand der Anteil der katholischen Einwohnerinnen und Einwohner aus einer Minderheit und in $10.9 \%$ der Fälle schätzten die Betroffenen den Anteil der katholischen Bevölkerung auf ungefähr 50 \% ein (siehe Tabelle 1).

Zudem war von Relevanz, in welchem Alter die Betroffenen die sexuellen Misshandlungen erdulden mussten (offenes Antwortformat). Im 
Durchschnitt berichteten diese ein Alter von $M=10.93$ Jahren $(S D=3.33)$ bei der ersten Missbrauchserfahrung. Die mittlere Dauer der Missbrauchshandlungen ließ sich mit ungefähr drei Jahren beziffern. Die Betroffenen waren demnach bei der letzten Missbrauchshandlung durchschnittlich $M=13.80$ Jahre $(S D=3.48)$ alt. Drei Befragte machten keine Angabe zu ihrem Alter zum Zeitpunkt der letzten Viktimisierung und für zehn Betroffene ließ sich die Dauer der Missbrauchserfahrung nicht bestimmen.

Wie in Abbildung 1 veranschaulicht, erfolgten sowohl Beginn als auch Ende der Viktimisierung(en) in gut jedem zweiten Fall im Alter zwischen 11 und 15 Jahren. $\mathrm{Zu}$ ähnlichen Ergebnissen gelangte beispielsweise das Team des John Jay College (2004): Dort hatten $62.3 \%$ der Betroffenen ein Alter zwischen 11 und 15 Jahren bei einem Mittelwert von $M=12.6$ Jahren.

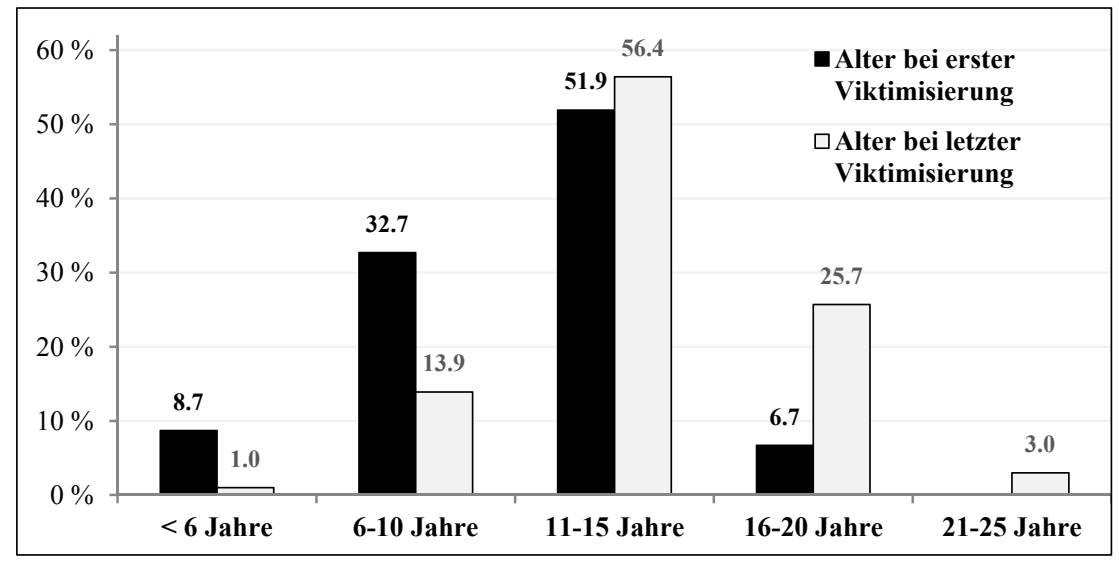

Abbildung 1. Kategorisierte Angaben der Betroffenen zu ihrem Alter zum Zeitpunkt der ersten und der letzten Viktimisierung in gültigen Prozent $(N \geq 101)$

Weitere Analysen ergaben keine Zusammenhänge von Erst- und Letztviktimisierungsalter oder der Missbrauchsdauer mit dem Geschlecht der Betroffenen, alle $p>.489$. Demzufolge widerfuhren männlichen und weiblichen Betroffenen die erste und letzte Viktimisierungshandlung durchschnittlich im gleichen Alter und es bestanden auch keine Unterschiede in der mittleren Dauer des Missbrauchs in Abhängigkeit vom Geschlecht der Betroffenen. 
Signifikante Unterschiede zeigten sich jedoch bei der Zusammenfassung der Missbrauchsfälle nach dem damaligen Lebensmittelpunkt der Betroffenen: Diejenigen $n=51$ Betroffenen, die zum Zeitpunkt des Missbrauchs in einem institutionellen Kontext (Heim oder Internat) gelebt hatten, waren bei der letzten Missbrauchshandlung durchschnittlich älter $(M=14.68, S D=2.85)$ als diejenigen $n=53$ Betroffenen, die während des Missbrauchs nicht in einer derartigen Institution gelebt hatten $(M=12.94$, $S D=3.84), t(99)=92.21, p=.011, d=0.52 .{ }^{3}$ Zwar besagt die vorliegende Kategorisierung nicht zweifelsfrei, dass der sexuelle Missbrauch innerhalb der entsprechenden Institution stattgefunden hatte. Aufgrund der großen Wahrscheinlichkeit kann diese Variable jedoch als adäquate Näherung betrachtet werden.

Unterschiede im Alter bei der ersten Viktimisierung und in der Missbrauchsdauer waren hingegen nicht nachweisbar, beide $p>.123$. Dies ließ sich durch eine genauere Betrachtung des institutionellen Missbrauchskontext aufklären. Dabei fiel auf, dass Betroffene, die zum Zeitpunkt des sexuellen Missbrauchs in einem Internat gelebt hatten, im Mittel signifikant später $(M=13.10, S D=1.77), t(49)=3.88, p<.001, d=1.14$, und signifikant kürzer $(M=1.83, S D=1.79), t(43)=2.55, p=.014, d=0.80$, viktimisiert wurden als Betroffene, die zum Zeitpunkt des Missbrauchs in einem Heim gelebt hatten. Diesen widerfuhr die erste sexuelle Missbrauchshandlung durchschnittlich im Alter von $M=10.03$ Jahren $(S D=3.23)$, die mittlere Dauer betrug hier $M=4.00$ Jahre $(S D=3.28)$. Betroffene im nicht-institutionellen Kontext hatten zum Zeitpunkt der ersten Viktimisierung im Mittel ein Alter von $M=10.64$ Jahren $(S D=3.51)$; durchschnittlich dauerte die Viktimisierung hier $M=2.27$ Jahre $(S D=2.47)$ an. Dass sich hinsichtlich des Alters der Betroffenen bei der letzten Viktimisierung diesbezüglich kein Unterschied nachweisen ließ, $t(48)<1$, ist demzufolge darauf zurückzuführen, dass Betroffene im Internatskontext mit einem vergleichsweise höheren Alter zum ersten Mal vik-

3 Mit dem $t$-Test lässt sich untersuchen, ob ein Unterschied zwischen zwei StichprobenMittelwerten zufällig oder statistisch bedeutsam ist. Der $p$-Wert liefert in diesem $\mathrm{Zu}$ sammenhang Informationen über die Wahrscheinlichkeit, dass die beobachtete Teststatistik unter Annahme der Nullhypothese den beobachteten oder einen extremeren Wert annimmt. Als Wahrscheinlichkeitsmaß kann $p$ zwischen 0 und 1 variieren. Legt man ein Signifikanzniveau von $\alpha=5 \%$ zugrunde, kann man ab einem $p$-Wert von $\leq .050$ von statistischer Signifikanz sprechen. Bei dem Kennwert $d$ (Cohen's d) handelt es sich um ein Effektstärkenmaß für die Bedeutsamkeit eines beobachteten Unterschieds. Nach Cohen (1988) gelten Werte bis $d=0.20$ als kleine, Werte bis $d=0.50$ als mittlere und Werte ab $d=0.80$ als große Effekte. 
timisiert wurden, dafür jedoch über einen kürzeren Zeitraum, während das Gegenteil auf Betroffene im Heimkontext und Betroffene, die außerhalb eines institutionellen Kontexts missbraucht wurden, zutraf.

Zur weiteren Spezifikation der Umstände, in welchen sich die Täterinnen bzw. Täter den Betroffenen genähert hatten, wurden die Gelegenheiten zum persönlichen Erstkontakt fokussiert und erfragt, wie die Betroffenen die Täterin bzw. den Täter kennengelernt hatten (siehe Tabelle 2). Um genauere Informationen hinsichtlich des Annäherns durch die Täterinnen bzw. Täter zu erhalten, die sich nicht innerhalb eines institutionellen Kontexts ereignet hatten, wurden die Angaben derjenigen Betroffenen genauer betrachtet, die außerhalb eines institutionellen Kontexts viktimisiert worden waren.

Tabelle 2. Angaben der Betroffenen zum ersten Aufeinandertreffen mit den Täterinnen bzw. Tätern in gültigen Prozent $(N=104)$

\section{Missbrauchskontext}

\begin{tabular}{|c|c|c|c|}
\hline & $\begin{array}{r}\text { Gesamt } \\
(N=104)\end{array}$ & $\begin{array}{r}\text { Institutionell } \\
(n=51)\end{array}$ & $\begin{array}{r}\text { Nicht-institutionell } \\
(n=53)\end{array}$ \\
\hline Heim & $27.9 \%$ & $56.9 \%$ & - \\
\hline Sonstiges & $14.4 \%$ & $19.6 \%$ & $9.4 \%$ \\
\hline $\begin{array}{l}\text { Gottesdienst, } \\
\text { Beichte, Seelsorge }\end{array}$ & $24.0 \%$ & $13.7 \%$ & $34.0 \%$ \\
\hline $\begin{array}{l}\text { Religionsunterricht, } \\
\text { sonstiger Schul-/ } \\
\text { Nachhilfeunterricht }\end{array}$ & $14.4 \%$ & $5.9 \%$ & $22.6 \%$ \\
\hline $\begin{array}{l}\text { Durch die eigene } \\
\text { Familie (z. B. Freund- } \\
\text { schaft, Bekanntschaft) }\end{array}$ & $9.6 \%$ & - & $18.9 \%$ \\
\hline $\begin{array}{l}\text { Messdienerunterricht/ } \\
\text { Ministrantendienste }\end{array}$ & $6.7 \%$ & - & $13.2 \%$ \\
\hline Jugendfreizeit & $1.9 \%$ & $2.0 \%$ & $1.9 \%$ \\
\hline Jugendtreff & $1.0 \%$ & $2.0 \%$ & - \\
\hline
\end{tabular}

Neben den vorgegebenen Antwortoptionen bestand die Möglichkeit, individuelle Antworten in der Kategorie „Sonstiges“ näher zu spezifizieren. Erneut gelangte die Bedeutung von Heim- und Internatserfahrungen in den Fokus, da die meisten Angaben der Betroffenen (27.9\%) ein Kennenler- 
nen im Heim beinhalteten. Darüber hinaus wurde die vielfach genutzte Kategorie „Sonstiges“ (14.4 \%) durch die Nennung verschiedener Internate dominiert.

Insgesamt waren der Gottesdienst bzw. andere religiöse Aktivitäten eine häufige Quelle des Kontakts zwischen den Täterinnen bzw. Tätern und den Betroffenen (24.0\%). Dies traf sowohl auf den institutionellen $(13.7 \%)$, aber vor allem auf den nicht-institutionellen Kontext (34.0\%) $\mathrm{zu}$.

Weiterhin wurden von Betroffenen, die außerhalb eines institutionellen Kontexts sexuelle Gewalt erlebt hatten, der Religions- oder sonstige Schulunterricht (22.6\%) sowie die Bekanntschaft der beschuldigten katholischen Geistlichen mit den Familien der Betroffenen (18.9\%) als soziale Schnittpunkte definiert. 13.2 \% dieser Betroffenen hatten die Täterinnen bzw. Täter im Messdienerunterricht oder bei Ministrantendiensten kennengelernt. Seltenere Gelegenheiten des Kennenlernens stellten für beide Betroffenengruppen Jugendtreffs und Jugendfreizeiten mit insgesamt $2.9 \%$ Nennungshäufigkeit dar. Im Forschungsbericht des John Jay College stellten kirchliche Aktivitäten wie die Messe (für weibliche Betroffene $27.1 \%$, für männliche Betroffene $33.8 \%$ ) oder Altardienste (für weibliche Betroffene $10.7 \%$, für männliche Betroffene $12.3 \%$ ) ebenfalls mehrheitlich die Quelle des ersten Kontakts zwischen Täterinnen bzw. Tätern und Betroffenen dar (Terry et al., 2011).

\section{II.2 Wer waren die Täterinnen und Täter?}

Zur Erstellung eines Tatprofils wurde zunächst erfasst, durch wie viele Geistliche der katholischen Kirche die Betroffenen sexuelle Gewalt erlebt hatten. Die Befragten konnten angeben, ob sie (1) durch einen oder durch verschiedene katholische Geistliche missbraucht worden waren. Bei mehreren Täterinnen bzw. Tätern wurde zusätzlich erhoben, ob sich diese (2) im selben oder (3) in unterschiedlichen Zeiträumen an den Betroffenen vergangen hatten. Als Bearbeitungshinweis für die anschließenden Fragen zum Tatgeschehen wurde den Befragten mitgeteilt, dass sie ihre Angaben im Falle multiplen Missbrauchs auf den von ihnen als am schlimmsten erlebten sexuellen Missbrauch beziehen sollten. 


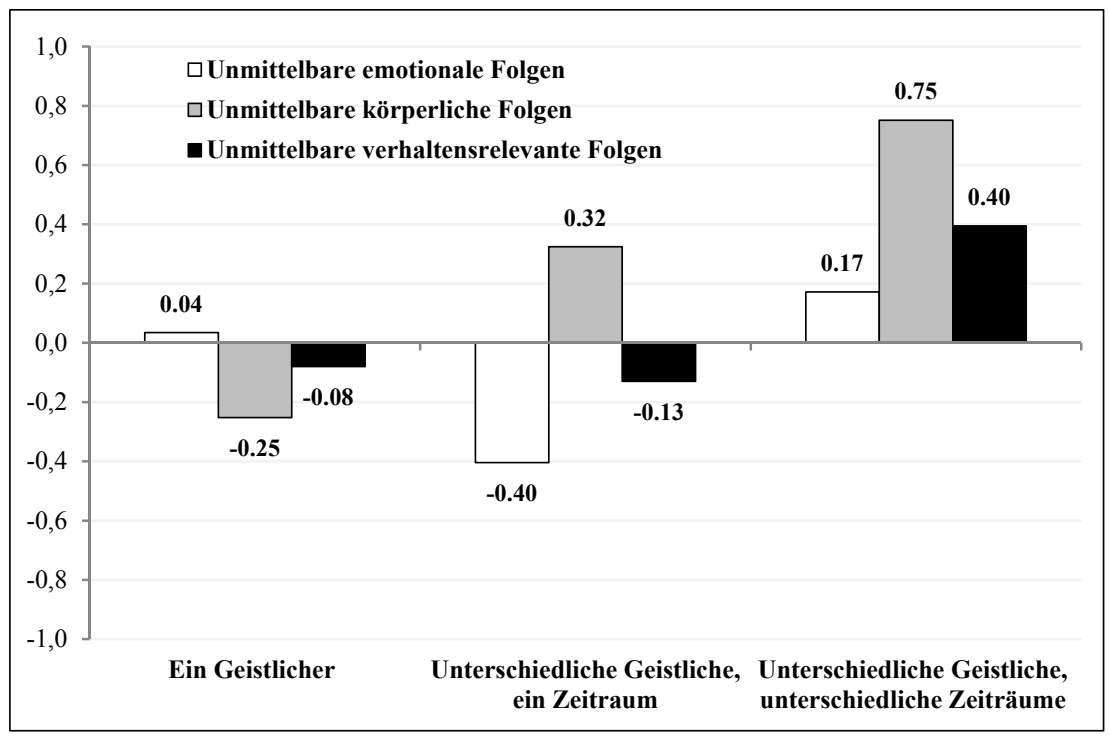

Abbildung 2. Angaben der Betroffenen zu unmittelbar erlebten emotionalen, körperlichen und verhaltensrelevanten Folgen des sexuellen Missbrauchs in Abhängigkeit von der Anzahl der Missbrauchstäterinnen bzw. -täter ( $z$-standardisierte Summenscores; $N=100)^{4}$

Mehr als zwei Drittel der Betroffenen (67.6\%) beschrieben, dass die sexuellen Misshandlungen durch einen einzelnen Geistlichen der katholischen Kirche verübt worden waren. Insgesamt benannten $32.4 \%$ der Be-

Für die Auswertung der unmittelbaren Folgen haben wir sogenannte $z$-standardisierte Summenscores gebildet: Zunächst wurden alle von den Betroffenen benannten Folgen in ihrer Kategorie (emotional, verhaltensrelevant und körperlich) addiert. Da für jede Kategorie eine unterschiedliche Anzahl potenziell erlebter Folgen zur Auswahl stand, wurden die drei Summenwerte in einem nächsten Schritt $z$-standardisiert. Konkret wurde jeder Messwert durch Subtraktion des Mittelwerts und Division durch die Standardabweichung der zugrunde liegenden Verteilung in einen $z$-Wert überführt. Daraus resultierte eine sogenannte Standardnormalverteilung mit einem Mittelwert von 0 und einer Standardabweichung von 1. Durch diese Transformation ließen sich die Angaben zu den drei unterschiedlichen Arten erlebter Folgen direkt miteinander vergleichen. Dass dabei im Ergebnis auch negative Werte auftreten, ist der $z$ Transformation geschuldet und keinesfalls absolut zu interpretieren (die Betroffenen berichteten zwischen 0 und 20 unterschiedliche emotionale, zwischen 0 und 9 körperliche und zwischen 0 und 7 verhaltensrelevante unmittelbare Folgen des sexuellen Missbrauchs, siehe auch Hellmann, Dinkelborg \& Fernau, 2014; Kap. 6 in diesem Band). 
troffenen unterschiedliche Geistliche als Täterinnen bzw. Täter des sexuellen Missbrauchs. Dieser erfolgte in 15.7 \% der Fälle in einem einzelnen Zeitraum und in $16.7 \%$ der Fälle in unterschiedlichen Zeiträumen. Von besonderer Relevanz war die Anzahl der Delinquentinnen bzw. Delinquenten unter anderem, da sie sich signifikant auf das Ausmaß der im unmittelbaren Zusammenhang mit der Tat erlebten emotionalen, körperlichen und verhaltensrelevanten Folgen der Betroffenen auswirkte (siehe Abbildung 2).

Betroffene, die in unabhängigen Zeiträumen durch unterschiedliche Täterinnen bzw. Täter viktimisiert worden waren, berichteten beispielsweise in besonders starkem Ausmaß von unmittelbaren körperlichen Beeinträchtigungen infolge der Viktimisierung(en), $F(2,97)=7.98, p=.001$, $\eta_{\mathrm{p}}{ }^{2}=.140 .^{5}$ Zudem wiesen diese Betroffenen zum Befragungszeitpunkt mit größerer Wahrscheinlichkeit eine Posttraumatische Belastungsstörung, $F(2,97)=8.39, p<.001, \eta_{\mathrm{p}}{ }^{2}=.147$, oder andere psychische Beeinträchtigungen auf, $F(2,97)=4.78, p=.010, \eta_{\mathrm{p}}{ }^{2}=.090$ (siehe auch Hellmann et al., 2014; Kap. 6 in diesem Band).

Darüber hinaus zeigte sich, dass Betroffene, die zur Zeit des Missbrauchs in einem institutionellen $v s$. nicht-institutionellen Kontext gelebt hatten, signifikant häufiger durch verschiedene Geistliche zum selben Zeitpunkt (24.0\% vs. $7.7 \%$ ) und durch verschiedene Geistliche zu unterschiedlichen Zeitpunkten ( $28.0 \%$ vs. $5.8 \%$ ) viktimisiert worden waren und entsprechend seltener sexuellen Missbrauch durch eine Einzeltäterin bzw. einen Einzeltäter erlebten $(48.0 \%$ vs. $86.5 \%)$, $\chi^{2}(2, N=102)=17.48, p<.001, \mathrm{CI}=.414{ }^{6}{ }^{6}$ Eine genauere Betrachtung

5 Bei dem $F$-Wert handelt es sich um die Prüfgröße der Varianzanalyse (F-Test), mit der Unterschiedshypothesen getestet werden können. Wenn $F$ einen kleineren Wert als 1 annimmt, bestehen mit einer im Vorfeld festgelegten Wahrscheinlichkeit zwischen den verglichenen Gruppen keine signifikanten Unterschiede in Hinblick auf die betrachtete Variable. Die Größe eines beobachteten Effekts lässt sich unter anderem anhand der Effektstärke $\eta_{\mathrm{p}}{ }^{2}$ bestimmen. Weiterführende Erläuterungen finden sich beispielsweise bei Bortz (2005).

6 Mithilfe eines $\chi^{2}$-Tests lässt sich unter anderem bestimmen, ob ein Unterschied zwischen zwei Gruppen (z. B. Frauen vs. Männer) bezüglich eines bestimmten Merkmals (z. B. Tatzeitraum) besteht. Der $\chi^{2}$-Wert stellt dabei ein Maß für die Abweichung vom Erwartungswert dar. Unter Berücksichtigung der Freiheitsgrade und der Stichprobengröße kann geprüft werden, ob ein Merkmal unabhängig von den betrachteten Gruppen variiert. Die Abkürzung „CI“ steht für Cramér's Index (Cramér's V). Dabei handelt es sich um ein Maß für den Zusammenhang zwischen zwei nominalen Variablen mit mehr als zwei Ausprägungen. CI kann zwischen 0 und 1 variieren. Je höher der Wert von CI ist, desto stärker ist der Zusammenhang zwischen den betrachteten Variablen bzw. desto größer ist der Effekt. Bei zweistufigen nominalen (dichotomen) Va- 
der Wohnsituation zum Zeitpunkt des sexuellen Missbrauchs ergab zudem Unterschiede in der Anzahl der Täterinnen bzw. Täter und den jeweiligen Missbrauchszeiträumen zwischen denjenigen Betroffenen, die ihre Kindheit (teilweise) in einem Heim vs. einem Internat verbracht hatten (siehe Tabelle 3), $\chi^{2}(4, N=102)=34.99, p<.001, \mathrm{CI}=.414$.

Tabelle 3. Angaben der Betroffenen zur Anzahl der Missbrauchstäterinnen bzw. -täter und den Missbrauchszeiträumen in gültigen Prozent $(N=102)$

\begin{tabular}{lrrr}
\hline & \multicolumn{2}{c}{ Missbrauchskontext } \\
& $\begin{array}{r}\text { Heim } \\
(n=31)\end{array}$ & $\begin{array}{l}\text { Internat } \\
(n=19)\end{array}$ & $\begin{array}{r}\text { Nicht-institutionell } \\
(n=52)\end{array}$ \\
\hline $\begin{array}{l}\text { Ein Geistlicher } \\
\begin{array}{l}\text { Unterschiedliche Geistliche } \\
\text { in einem Zeitraum }\end{array}\end{array}$ & $32.3 \%$ & $73.7 \%$ & $86.5 \%$ \\
$\begin{array}{l}\text { Unterschiedliche Geistliche } \\
\text { in unterschiedlichen Zeiträumen }\end{array}$ & $22.6 \%$ & $26.3 \%$ & $7.7 \%$ \\
\hline
\end{tabular}

Betroffene, die zum Missbrauchszeitpunkt in einem Internat gelebt hatten, und solche, die außerhalb eines institutionellen Kontexts gelebt hatten, wurden in etwa gleich häufig von einer einzelnen Täterin bzw. einem einzelnen Täter viktimisiert (73.3 \% bzw. $86.5 \%$ ). Auf Betroffene, die zum Missbrauchszeitpunkt in einem Heim gelebt hatten, traf dies hingegen deutlich seltener zu (32.3\%). Hier überwog stattdessen die Häufigkeit unterschiedlicher Täterinnen bzw. Täter, welche die Betroffenen in unterschiedlichen Zeiträumen missbraucht hatten (45.2 \%). Solche Fälle fanden sich in der vorliegenden Stichprobe wiederum im Internatskontext gar nicht und außerhalb des institutionellen Kontexts in deutlicher Minderheit (5.8 \%). Fälle von sexuellem Missbrauch, die durch unterschiedliche Personen im selben Zeitraum verübt worden waren, lagen dagegen im Heimkontext $(22.6 \%)$ und im Internatskontext $(26.3 \%)$ häufiger vor im Vergleich zum außerinstitutionellen Kontext (7.7\%).

riablen wird der $\phi$-Koeffizient als Effektstärkenmaß verwendet. Konventionell gelten Werte bis $\phi=.100$ als kleine, Werte bis $\phi=.300$ als mittlere und Werte ab $\phi=.500$ als große Effekte. Weiterführende Erläuterungen finden sich beispielsweise bei Bortz (2005). 
Zur Spezifikation der Funktion(en) der Täterinnen bzw. Täter innerhalb der katholischen Kirche wurden unterschiedliche (Kirchenamts-)Kategorien offeriert (siehe Abbildung 3). Die Option „Sonstiges“ bot Raum für die Darstellung weiterer Funktionen der Delinquentinnen bzw. Delinquenten. Bei Unsicherheit über die Stellung der Täterinnen bzw. Täter konnte die Kategorie „Ich weiß es nicht“ gewählt werden. Da katholische Geistliche häufig verschiedenen Aufgaben nachkommen, bestand die Möglichkeit, mehrere Funktionen zu benennen, sodass insgesamt 188 Antworten generiert wurden.

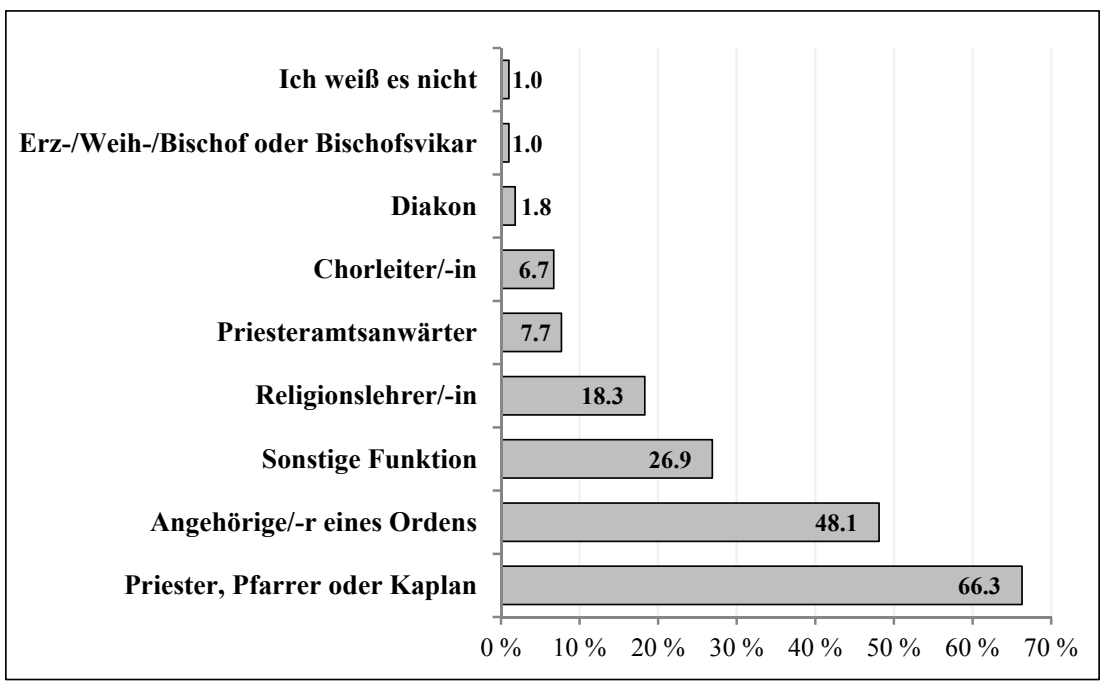

Abbildung 3. Angaben der Betroffenen zu der kirchlichen Funktion der Täterinnen bzw. Täter, die den sexuellen Missbrauch verübt hatten, in gültigen Prozent (Mehrfachnennungen möglich; $N=104$ )

Sowohl die umfassenden Analysen der Anlaufstelle zur Aufarbeitung des sexuellen Missbrauchs der Universität Ulm (Fegert et al., 2011) und des John Jay College (2004; Terry et al., 2011) als auch die vorliegende Befragung ergaben, dass der Großteil der als Täterinnen bzw. Täter benannten Personen (66.3 \%) das Amt eines Priesters, Pfarrers oder Kaplans bekleidete. Weiterhin beschuldigte knapp die Hälfte der Betroffenen weibliche oder männliche Ordensangehörige des sexuellen Missbrauchs (48.1\%). Die offene Antwortkategorie „Sonstige Funktion“ wurde von mehr als jeder bzw. jedem vierten Befragten genutzt (26.9\%). Diese Kategorie war vor allem durch die Nennung von Institutionsleitungen und 
Direktorinnen bzw. Direktoren von Heimen und Internaten geprägt. Etwas seltener (18.3\%) wurden Delinquentinnen und Delinquenten benannt, die als Religionslehrerinnen bzw. -lehrer fungierten. Priesteramtsanwärter (7.7 \%), Chorleiterinnen bzw. -leiter (6.7 \%), Diakone (4.8\%) und besonders (Erz-/Weih-)Bischöfe und Bischofsvikare (1.0\%) wurden verhältnismäßig selten als Täterinnen bzw. Täter sexuellen Missbrauchs spezifiziert.

Bei der Interpretation dieser Angaben ist zu berücksichtigen, dass es sich hier um Mehrfachantworten handelt. Es kann also ausgeschlossen werden, dass eine Person als Täterin bzw. Täter von sexuellem Missbrauch benannt wurde, bei der es sich nicht um einen katholischen Geistlichen handelte. Beispielsweise lagen keine Fälle vor, in denen der Missbrauch den Angaben der Betroffenen zufolge durch eine Person begangen worden war, die ausschließlich Religionslehrerin bzw. -lehrer war und somit keine explizite Funktion im Rahmen der katholischen Kirche innehatte.

Die häufige Nennung von Priestern, Pfarrern und Kaplänen indizierte, dass die Mehrheit der Beschuldigten männlichen Geschlechts war, da diese Kirchenämter in der katholischen Kirche für Frauen nicht zugänglich sind. Aufgrund der Angaben der Betroffenen konnte das Geschlecht der viktimisierenden Person(en) eindeutig in 82 Fällen ermittelt werden: Der sexuelle Missbrauch durch ausschließlich weibliche katholische Geistliche wurde in drei Fällen (3.7\%) berichtet. Weitere sechs Betroffene (7.3\%) gaben an, sowohl durch weibliche als auch durch männliche katholische Geistliche sexuelle Gewalt erfahren zu haben. Die große Mehrheit der Missbrauchstaten wurde mit $89.0 \%$ ausschließlich durch männliche Täter begangen.

Bei der Interpretation dieser Häufigkeiten ist zum einen zu berücksichtigen, dass nicht explizit nach dem Geschlecht der Täterin bzw. des Täters gefragt worden war. Zum anderen ist aufgrund des Aufrufs, sich an einer „Studie zu sexuellem Missbrauch durch katholische Geistliche“" zu beteiligen, von einer besonderen Selektivität auszugehen: Da Ordensschwestern nicht explizit als Täterinnen sexuellen Kindesmissbrauchs angeführt worden waren, sind weibliche Missbrauchstäterinnen aus der katholischen Kirche in der gewonnenen Stichprobe möglicherweise besonders unterrepräsentiert. Gleichzeitig ist in diesem Zusammenhang darauf hinzuweisen, dass auch in einer deutschlandweiten Repräsentativbefragung zu sexuellem Missbrauch im Allgemeinen männliche Täter deutlich häufiger als weibliche Täterinnen von den Betroffenen beschuldigt wurden (siehe Stadler et al., 2012). In ihrer österreichischen Befragung Betroffener sexu- 
ellen Missbrauchs innerhalb der katholischen Kirche berichtete beispielsweise Lueger-Schuster (2012) von einem etwas niedrigeren Anteil männlicher Täter von $77.0 \%$. Dies verstärkt den Hinweis darauf, dass sich Betroffene von sexuellem Missbrauch durch Ordensschwestern unter Umständen von dem Aufruf des KFN zur Beteiligung an der Studie seltener angesprochen gefühlt hatten.

Zur spezifischeren Charakterisierung der Täterinnen bzw. Täter wurden die Betroffenen des Weiteren im offenen Antwortformat um eine Einschätzung des Alters der Beschuldigten gebeten. Das durchschnittliche Alter der Täterinnen bzw. Täter zum Missbrauchsbeginn lag bei $M=40.79$ Jahren $(S D=10.12)$ und war durch eine Altersspanne von 19 bis 65 Jahren gekennzeichnet. Fünf Betroffene machten keine Angabe zum Alter der Delinquentinnen bzw. Delinquenten. Das Alter der Beschuldigten bei der letzten Missbrauchshandlung wurde auf Basis von 94 gültigen Aussagen ermittelt. Die Täterinnen bzw. Täter waren den Angaben der Betroffenen zufolge zum Ende des Missbrauchs zwischen 22 und 68 Jahren alt, das durchschnittliche Alter belief sich auf $M=44.38$ Jahre $(S D=9.87)$. Einschränkend ist in diesem Zusammenhang anzumerken, dass es sich hier um retrospektive Schätzungen der Betroffenen handelt: Dabei ist zu berücksichtigen, dass Einschätzungen des Alters einer (deutlich älteren) erwachsenen Person aus Sicht eines Kindes unter Umständen fehlerbehaftet sind.

Zum Vergleich sei an dieser Stelle auf die Ergebnisse des John Jay College (2004) zum innerkirchlichen sexuellen Missbrauch in den USA verwiesen: Dort lag das Alter der Täterinnen bzw. Täter zum Zeitpunkt der ersten sexuellen Viktimisierung mehrheitlich zwischen 25 und 44 Jahren (70.3 \%). Zu berücksichtigen ist bei diesem Vergleich, dass die im Rahmen der vorliegenden Studie befragten Betroffenen unter Umständen nicht die ersten Kinder waren, an denen sich die jeweiligen Täterinnen und Täter vergangen hatten. Damit und unter Berücksichtigung der zuvor genannten Einschränkungen bei der (Erinnerung an die) Einschätzung des Alters einer deutlich älteren Person ist das erhöhte Alter der durch die Betroffenen der vorliegenden Befragung benannten Täterinnen und Täter sexuellen Missbrauchs zu erklären.

Darüber hinaus war von Interesse, inwiefern die Täterinnen bzw. Täter der Familie der Betroffenen bekannt waren: Mehr als zwei Drittel der Betroffenen $(68.3 \%)$ gaben an, dass ihre Familien die Täterinnen bzw. Täter gekannt hatten. Diejenigen $n=71$ Personen, die eine Bekanntschaft zwischen ihrer Familie und der Täterin bzw. dem Täter bestätigt hatten, wurden diesbezüglich um detailliertere Einschätzungen gebeten. Die folgen- 
den Prozentwerte wurden aus den zustimmenden Antwortoptionen ,trifft

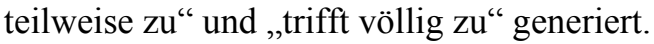

Wie in Abbildung 4 veranschaulicht, waren die Betroffenen größtenteils der Ansicht, ihre Eltern seien (zumindest teilweise) glücklich über oder stolz auf den Kontakt zwischen ihrem Kind und der Täterin bzw. dem Täter gewesen (81.2\%) und hätten (zumindest teilweise) eine hohe Meinung von selbigen gehabt (87.9\%). Auch Benkert und Doyle (2009) postulierten in diesem Zusammenhang, dass es in vielen Familien als Ehre angesehen wurde, wenn ein Geistlicher gerade das eigene Kind mit besonderer Aufmerksamkeit bedachte. Da vor allem Geistlichen moralische, ethische und religiöse Erhabenheit zugeschrieben werde (Plante, 1996), würde ebendiese besondere Aufmerksamkeit vermutlich nicht weiter hinterfragt.

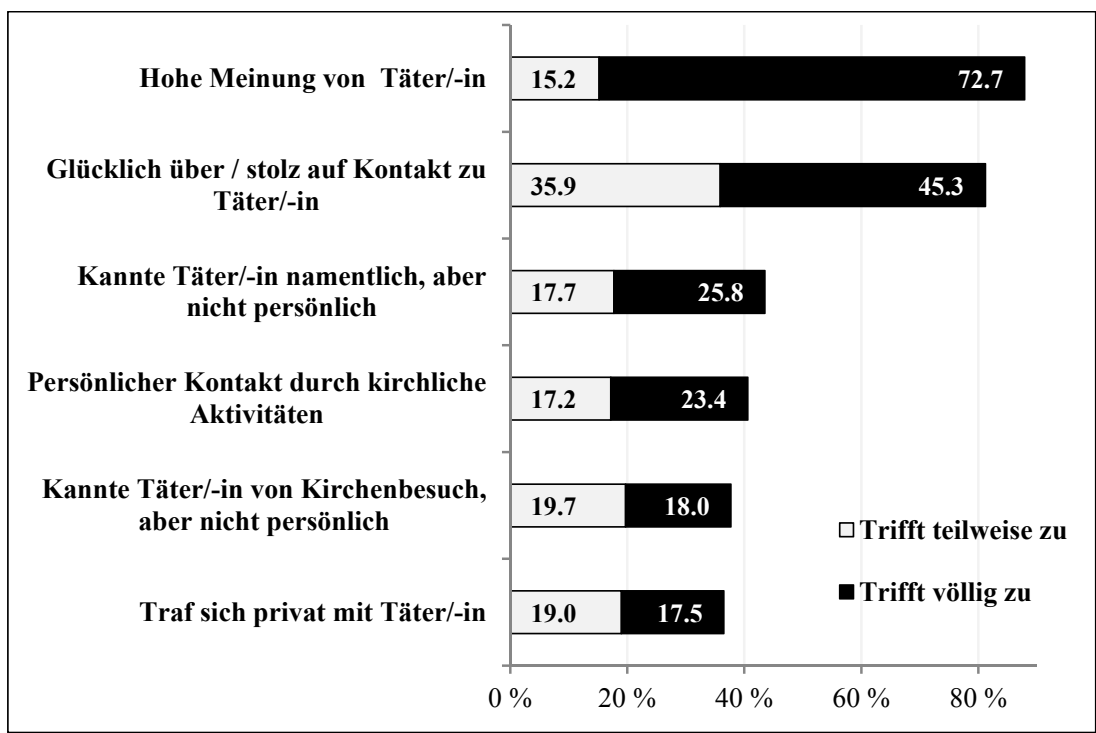

Abbildung 4. Angaben der Betroffenen zur Beziehung zwischen ihren Eltern und den Täterinnen bzw. Tätern in gültigen Prozent $(N \geq 61)$

Zudem berichteten die Betroffenen häufig, dass ihre Eltern (teilweise) persönlichen Kontakt im Rahmen kirchlicher Aktivitäten mit den Beschuldigten pflegten $(40.6 \%)$ oder sich auch privat mit den Täterinnen bzw. Tätern trafen $(36.5 \%)$. Nach Einschätzung der Betroffenen kannten einige Eltern die beschuldigten Geistlichen nur namentlich (43.5\%) bzw. durch 
Kirchenbesuche (37.7 \%), pflegten jedoch keinen persönlichen Kontakt zu ihnen.

\section{II.3 Was ist passiert?}

Die folgenden Abschnitte setzen sich ausführlich mit den unterschiedlichen Facetten der sexuellen Missbrauchshandlungen auseinander. Zunächst werden die Tatzeiträume und Tatorte vorgestellt. Des Weiteren wird berichtet, welche Mechanismen und Druckmittel dem ersten sexuellen Übergriff zugrunde lagen. Ein zentraler Bestandteil umfasst die Schilderung der spezifischen Tathandlungen sowie deren religiöse Einbettung und Verbindungen $\mathrm{zu}$ Alkohol und Drogen sowie zu pornografischen Aufnahmen. Neben den sexualisierten Gewalthandlungen werden auch physische, verbale und psychische Druckmittel sowie spezielle Zuwendungen durch die Täterinnen bzw. Täter thematisiert.

\section{Tatzeiträume}

Die Zeiträume, welche die Betroffenen mit der (subjektiv schlimmsten) Missbrauchserfahrung verbanden, wurden anhand einer offenen Frage erhoben und in vier Kategorien zusammengefasst. Den Angaben der Betroffenen zufolge fanden die sexuellen Übergriffe zu annähernd gleichen Teilen von 1949 bis 1959 (26.0\%), 1960 bis 1969 (29.8\%) und 1970 bis 1979 (27.9 \%) statt. In diesem Zusammenhang ist zu berücksichtigen, dass gerade ältere Betroffene, deren Missbrauchserfahrungen bis in die 1940er und 1950er Jahre zurückreichen, unter Umständen seltener erreicht wurden als jüngere Betroffene und diese daher im vorliegenden Rahmen möglicherweise unterrepräsentiert sind. Mit Beginn der 1980er Jahre war die Zahl der im Rahmen dieser Studie erfassten sexuellen Missbrauchsfälle hingegen deutlich rückläufig (1980 bis 1993: 16.4\%). Dieser rückläufige Trend wurde ebenso in dem umfassenden Bericht des John Jay College (2004) zum sexuellen Missbrauch Minderjähriger durch katholische Geistliche skizziert.

Unterschiede in den Tatzeiträumen in Abhängigkeit vom Geschlecht der Betroffenen ließen sich in der vorliegenden Studie nicht nachweisen, $\chi^{2}(3, N=103)=1.29, p=.732$. Allerdings zeigte sich, dass solche Missbrauchsfälle, die innerhalb einer Institution wie einem Internat oder einem Heim stattgefunden hatten, in den beiden am weitesten zurückliegenden 
Tatzeiträumen signifikant häufiger vorkamen als in den beiden jüngeren Dekaden, $\chi^{2}(3, N=104)=10.23, p=.017, \mathrm{CI}=.314$. Dieser Trend ließ sich für diejenigen Fälle, die außerhalb von Institutionen geschehen waren, in dieser Form nicht nachweisen (siehe Tabelle 4).

Tabelle 4. Kategorisierte Angaben der Betroffenen zum Tatzeitpunkt der ersten sexuellen Missbrauchshandlung in Abhängigkeit von einem institutionellen vs. nicht-institutionellen Kontext in gültigen Prozent $(N=104)$

\begin{tabular}{lrr}
\hline & \multicolumn{2}{c}{ Missbrauchskontext } \\
& Institutionell & Nicht-institutionell \\
\hline $1949-1959$ & $35.3 \%(n=18)$ & $17.0 \%(n=9)$ \\
$1960-1969$ & $35.3 \%(n=18)$ & $24.5 \%(n=13)$ \\
$1970-1979$ & $21.6 \%(n=11)$ & $34.0 \%(n=18)$ \\
$1980-1993$ & $7.8 \%(n=4)$ & $24.5 \%(n=13)$ \\
\hline
\end{tabular}

Diesen Angaben zufolge hat sich der Anteil an sexuellen Missbrauchsfällen durch katholische Geistliche innerhalb von Institutionen zwischen 1949 und 1993 deutlich reduziert. Dabei ist jedoch wiederum zu berücksichtigen, dass aufgrund der Selektivität der vorliegenden Stichprobe nur begrenzte Aussagen darüber getroffen werden können, ob der Anteil der Missbrauchsfälle durch katholische Geistliche in Heimen und Internaten generell im benannten Zeitraum zurückgegangen ist. Fegert et al. (2011) berichteten in diesem Zusammenhang, dass die Ergebnisse der Anlaufstelle der Unabhängigen Beauftragten zur Aufarbeitung des sexuellen Kindesmissbrauchs auf einen generellen Rückgang sexuellen Missbrauchs im kirchlichen Kontext hindeuteten. Die Daten der deutschlandweiten Repräsentativbefragung mit 16- bis 40-jährigen Personen aus dem Jahr 2011 zur Verbreitung des sexuellen Missbrauchs lassen sich ebenfalls in diesem Sinne interpretieren, da dort lediglich eine Person von 676 Betroffenen sexuellen Missbrauchs einen katholischen Geistlichen als Täter benannt hatte (Stadler et al., 2012). 


\section{Tatorte}

Um zu erfassen, wo bzw. in welchem Kontext der Missbrauch stattgefunden hatte, wurden 13 geschlossene Antwortvorgaben (siehe Tabelle 5) sowie die offene Antwortoption "Sonstiges“ offeriert. Da der sexuelle Missbrauch häufig an verschiedenen Orten verübt worden war, konnten mehrere Tatorte benannt werden, was in insgesamt 241 Nennungen diverser Missbrauchsörtlichkeiten resultierte. Analog zu den Betroffenenangaben zum Kennenlernen der Täterinnen bzw. Täter werden die gewonnenen Ergebnisse zu den Tatorten separat für Betroffenen dargestellt, die in einem institutionellen $v s$. nicht-institutionellen Kontext viktimisiert worden waren.

Tabelle 5. Angaben der Betroffenen zu Tatorten bzw. Kontexten der sexuellen Missbrauchshandlungen in gültigen Prozent (Mehrfachnennungen möglich; $N=104$ )

\begin{tabular}{|c|c|c|c|}
\hline & \multirow[b]{2}{*}{$\begin{array}{r}\text { Gesamt } \\
(N=104)\end{array}$} & \multicolumn{2}{|c|}{ Missbrauchskontext } \\
\hline & & $\begin{array}{r}\text { Institutionell } \\
(n=51)\end{array}$ & $\begin{array}{l}\text { Nicht-institutionell } \\
\qquad(n=53)\end{array}$ \\
\hline Bei Täter/-in zu Hause & $39.4 \%$ & $25.5 \%$ & $52.8 \%$ \\
\hline Sonstiges & $37.5 \%$ & $23.5 \%$ & $50.9 \%$ \\
\hline Im Heimgebäude & $27.9 \%$ & $51.0 \%$ & $5.7 \%$ \\
\hline Während einer Jugendfreizeit / Reise & $22.1 \%$ & $11.8 \%$ & $32.1 \%$ \\
\hline In Zusammenhang mit der Beichte & $21.2 \%$ & $27.5 \%$ & $15.1 \%$ \\
\hline Vor / nach Gottesdienst & $20.2 \%$ & $19.6 \%$ & $20.8 \%$ \\
\hline Im Internatsgebäude & $20.2 \%$ & $35.3 \%$ & $5.7 \%$ \\
\hline Vor / nach Messdienerunterricht & $10.6 \%$ & $7.8 \%$ & $13.2 \%$ \\
\hline $\begin{array}{l}\text { Vor / während / nach sportlicher } \\
\text { Aktivität }\end{array}$ & $7.7 \%$ & $5.9 \%$ & $9.4 \%$ \\
\hline $\begin{array}{l}\text { Vor / nach Religions-/ } \\
\text { Schulunterricht }\end{array}$ & $7.7 \%$ & $3.9 \%$ & $11.3 \%$ \\
\hline In der Schule & $6.7 \%$ & $2.0 \%$ & $11.3 \%$ \\
\hline Bei mir zu Hause & $4.8 \%$ & $2.0 \%$ & $7.5 \%$ \\
\hline Im Krankenhaus & $3.8 \%$ & $5.9 \%$ & $1.9 \%$ \\
\hline Vor / nach Musikveranstaltung & $1.9 \%$ & $3.9 \%$ & - \\
\hline
\end{tabular}


Aus den vorgegebenen Antwortkategorien wurden insgesamt das Zuhause der Täterinnen bzw. Täter (39.4\%) und das Heimgebäude (27.9 \%) am häufigsten als Tatkontexte der sexuellen Missbrauchshandlungen beschrieben. Die Häufigkeit in den Benennungen dieser beiden Tatkontexte variierte jedoch signifikant mit dem institutionellen $v s$. nichtinstitutionellen Lebensmittelpunkt der Betroffenen zum Zeitpunkt des Missbrauchs: Während gut die Hälfte der Betroffenen, die in einem außerinstitutionellen Kontext viktimisiert worden waren, als Tatort das Zuhause der Täterin bzw. des Täters benannten $(52.8 \%), \chi^{2}(1, N=104)=8.14$, $p=.004, \phi=.280$, stellte das Heimgebäude erwartungsgemäß den häufigsten Tatort bei Betroffenen dar, die zum Zeitpunkt des Missbrauchs in einem institutionellen Kontext gelebt hatten (51.0\%), $\chi^{2}(1, N=104)=26.55, p<.001, \phi=.505$.

Ebenso war der Unterschied in der Häufigkeit der Benennungen von Internatsgebäuden wenig überraschend (institutioneller Kontext: $35.3 \%$, nicht-institutioneller Kontext: $5.7 \%), \chi^{2}(1, N=104)=14.16, p<.001$, $\phi=.369$. Insgesamt berichtete ungefähr eine von fünf betroffenen Personen, die sexuellen Misshandlungen während einer Jugendfreizeit oder Reise $(22.1 \%)$, in Zusammenhang mit der Beichte $(21.2 \%)$ bzw. vor oder nach dem Gottesdienst (20.2\%) erlebt zu haben. Dabei wurde die Antwortoption „Jugendfreizeit / Reise“ signifikant häufiger von Betroffenen benannt, die den sexuellen Missbrauch nicht in einem institutionellen Kontext erlebt hatten (institutioneller Kontext: $11.8 \%$, nichtinstitutioneller Kontext: $32.1 \%), \chi^{2}(1, N=104)=6.23, p=.013, \phi=.245$.

Mehr als jeder bzw. jedem zehnten Betroffenen widerfuhren sexuelle Gewaltviktimisierungen in Verbindung mit dem Messdienerunterricht (10.6\%). Jeweils $7.7 \%$ der Betroffenen wurden vor, während oder nach einer sportlichen Aktivität bzw. vor oder nach dem Religions- bzw. Schulunterricht viktimisiert. Zu $6.7 \%$ erlebten die Betroffenen sexuelle Misshandlungen in der Schule. Das Zuhause der Betroffenen (4.8\%), Krankenhäuser (3.8\%) oder der Kontext von Musikveranstaltungen $(1.9 \%)$ waren eher selten Tatorte sexuellen Missbrauchs durch katholische Geistliche. Diesbezüglich bestanden keine Unterschiede in Abhängigkeit vom institutionellen $v s$. nicht-institutionellen Lebensmittelpunkt der Betroffenen zum Zeitpunkt des sexuellen Missbrauchs, alle $p>.056$.

Die offenen Antworten in der Kategorie „Sonstiges“, welche zu insgesamt $37.5 \%$ von den Betroffenen benannt worden war, beinhalteten unterschiedlichste Tatorte und Tatkontexte. Auffällig waren die häufigen Nennungen kirchlicher Räumlichkeiten (z. B. Sakristei, Pfarramt, Pfarrhaus, 
Kirche), katholischer Kindergärten sowie der Autos der Täterinnen bzw. Täter.

Dem Bericht des John Jay College (2004) ist ebenfalls zu entnehmen, dass dort der Großteil der sexuellen Gewaltviktimisierungen bei den Täterinnen bzw. Täter zu Hause stattgefunden hatte (40.9 \%). Dem österreichischen Bericht zu sexuellem Missbrauch innerhalb der katholischen Kirche zufolge waren wiederum Heime (39.6\%) bzw. Internate (30.3 \%) besonders häufig benannte Tatorte (Lueger-Schuster, 2012). Ein Vergleich mit einer Befragung zu sexuellem Missbrauch unabhängig vom Kirchenkontext (Stadler et al., 2012) ergab, dass auch dort die Wohnung des Täters bzw. der Täterin besonders häufig als Tatort benannt wurde (bei sexuellem Missbrauch mit Körperkontakt für weibliche Betroffene $24.4 \%$ und für männliche Betroffene $26.4 \%$ ). Allerdings überwogen hier die Wohnungen der Betroffenen insgesamt bei den Nennungen zum Tatort (bei weiblichen Betroffenen $35.2 \%$, bei männlichen Betroffenen $35.8 \%$ ).

\section{Initiierung der sexuellen Missbrauchshandlung}

Zur Spezifikation des Tathergangs beantworteten die Befragungsteilnehmerinnen und -teilnehmer unter anderem, wie es zur ersten Missbrauchshandlung gekommen war (siehe Abbildung 5). Neben den vier vorgegebenen Antwortoptionen stand wiederum die offene Antwortoption ,Sonstiges“ zur Verfügung, um gegebenenfalls zusätzlich die konkrete Anbahnung der Tat beschreiben zu können. Erneut waren die Befragten angehalten, alle Antwortoptionen zu markieren, die auf sie persönlich zutrafen, was zu insgesamt 171 Angaben führte.

Unabhängig von ihrem Geschlecht und dem Missbrauchskontext (beide $p>.161$ ) wählte mit insgesamt $70.2 \%$ die große Mehrheit der Betroffenen die Antwortoption ,hat das einfach getan“. Dies spiegelt besonders deutlich das bestehende Machtverhältnis bzw. die physische und psychische Überlegenheit der Täterin bzw. des Täters wider.

In insgesamt knapp einem Drittel der Fälle wandten die Täterinnen bzw. Täter bei der ersten Missbrauchshandlung Gewalt gegen die Betroffenen an $(28.8 \%)$. Diesbezüglich bestanden keine Unterschiede zwischen weiblichen und männlichen Betroffenen, $\chi^{2}(1, N=103)<1$. 


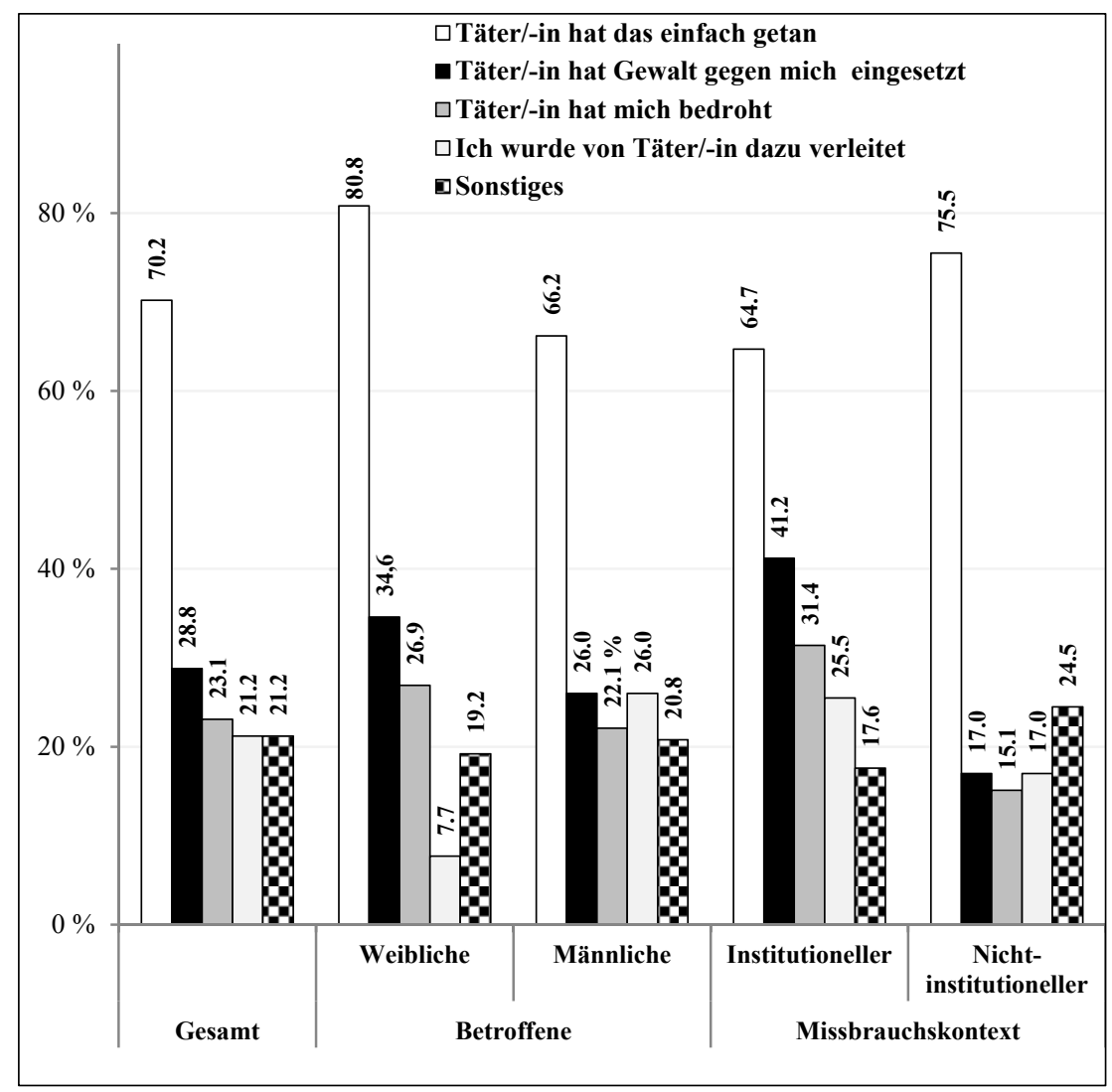

Abbildung 5. Angaben der Betroffenen zur Initiierung der ersten sexuellen Missbrauchshandlung nach Geschlecht der Betroffenen und institutionellem vs. nicht-institutionellem Missbrauchskontext in gültigen Prozent (Mehrfachnennungen möglich; $N \geq 103$ )

Allerdings setzten Täterinnen bzw. Täter im institutionellen Kontext den Angaben der Betroffenen zufolge bereits bei der ersten Missbrauchshandlung signifikant häufiger Gewalt gegen diese ein (41.2 \%) im Vergleich zu katholischen Geistlichen, welche die Betroffenen außerhalb eines institutionellen Kontexts missbraucht hatten $(17.0 \%), \chi^{2}(1, N=104)=7.41$, $p=.006, \phi=.267$. Die genauere Betrachtung ergab, dass vor allem Betroffene, die zum Missbrauchszeitpunkt in einem Heim gelebt hatten, physische Gewalt bei der Initiierung der ersten Missbrauchshandlung erlebten (54.8 \%), während diese Häufigkeit im Internatskontext verglichen mit 
dem außerinstitutionellen Kontext nur leicht erhöht war (20.0\%), $\chi^{2}(1, N=51)=9.09, p=.014, \phi=.346$.

Insgesamt gut zwei von zehn Betroffenen wurden eigenen Angaben zufolge durch Drohungen $(23.1 \%)$ genötigt. Dies traf nahezu in gleichem Ausmaß auf weibliche (26.9\%) wie auch auf männliche Betroffene $(26.0 \%) \mathrm{zu}, \chi^{2}(1, N=103)<1$. Demgegenüber erfuhren Betroffene, die im institutionellen Kontext viktimisiert worden waren, wiederum mehr als doppelt so häufig Drohungen durch die Täterin bzw. den Täter (31.4 \%) als Betroffene, denen außerhalb eines institutionellen Kontextes sexuelle Gewalt widerfahren war $(15.1 \%), \quad \chi^{2}(1, N=104)=3.88, \quad p=.049$, $\phi=.193$. Auch diesbezüglich zeigte sich, dass dieser Unterschied vor allem auf die Angaben derjenigen Betroffenen zurückzuführen war, die zum Missbrauchszeitpunkt in einem Heim gelebt hatten (Heim: $41.9 \%$, Internat: $15.0 \%), \chi^{2}(1, N=51)=4.10, p=.043, \phi=.283$.

Jeweils etwas mehr als ein Fünftel der Befragten (21.2\%) berichteten, die Täterin bzw. der Täter hätte sie bei der ersten Missbrauchshandlung dazu verleitet, oder wählten die Kategorie „Sonstiges“. Zu beachten ist bei der erstgenannten Antwortmöglichkeit, dass hier keineswegs eine Art Mitschuldigkeit der Betroffenen unterstellt werden soll. Die Vorüberlegungen, die zur Aufnahme dieser Antwortoption in den Fragebogen geführt hatten, zielten vor allem darauf ab, dass es sich bei sexuellem Kindesmissbrauch mitunter um ein komplexes Beziehungsgeflecht handelt und physische Gewaltanwendung oder Drohungen nicht notwendigerweise Bestandteil der Initiierung der sexuellen Missbrauchshandlung gewesen sein müssen. Aus dem Machtgefälle zwischen Täterinnen bzw. Tätern und Betroffenen ergibt sich, dass beispielsweise allein durch psychischen Druck Missbrauchshandlungen erzwungen werden können. Dies wiederum kann ebenso gravierende Folgen für die Betroffenen haben wie der durch physische Gewalt erzwungene Missbrauch zum Beispiel dadurch, dass die Betroffenen selbst sich eine Mitschuld an dem Geschehenen geben, entsprechende Reaktionen von Dritten erfahren oder auch erst stark verzögert realisieren, dass es sich bei dem, was mit ihnen geschehen ist, um sexuellen Missbrauch handelt.

In einer vergleichbaren Studie des KFN aus dem Jahr 2011 berichteten $39.2 \%$ der männlichen und $16.1 \%$ der weiblichen Betroffenen, sie wären von der Täterin bzw. dem Täter zu der ersten sexuellen Missbrauchshandlung verleitet worden (siehe Stadler et al., 2012). Dieser Geschlechterunterschied ließ sich noch stärker in der vorliegenden Befragung nachweisen: $26.0 \%$ der männlichen und $7.7 \%$ der weiblichen Betroffenen sexuellen Missbrauchs durch katholische Geistliche gaben an, dass sie zu der 
ersten Missbrauchshandlung verleitet worden waren, $\chi^{2}(1, N=103)=7.41, p=.049, \phi=.194$. Ob der Missbrauch innerhalb oder außerhalb eines institutionellen Kontexts stattgefunden hatte, war in diesem Zusammenhang nicht von statistisch signifikanter Bedeutung, $\chi^{2}(1, N=104)=1.13, p=.288$. Zu berücksichtigen ist bei dem Vergleich zwischen diesen beiden Studien des KFN unter anderem, dass in der vorliegenden Befragung eine selektive Stichprobe Betroffener rekrutiert wurde, die darüber hinaus einer anderen Alterskohorte angehörten, im Vergleich zu der KFN-Befragung aus dem Jahr 2011, in der eine deutschlandweit repräsentative Stichprobe im Alter zwischen 16 und 40 Jahren befragt wurde (siehe auch Hellmann, 2014).

Die 22 offenen Antworten zur Initiierung der ersten sexuellen Missbrauchshandlung beinhalteten die Beschreibung heterogener Vorgehensweisen, beispielsweise dass Heranlocken der Minderjährigen unter privaten oder religiösen Vorwänden. Unterschiede mit Blick auf das Geschlecht der Betroffenen oder danach, ob sich der Missbrauch im institutionellen Kontext abgespielt hatte, ließen sich in der Auswahlhäufigkeit der Kategorie „Sonstiges“ nicht nachweisen (beide $p>$.389). Anhand der benannten offenen Antworten lässt sich noch einmal die Bedeutung der Antwortkategorie „hat mich verleitet" aufzeigen: Eine betroffene Person schilderte hier beispielsweise, dass die erste Missbrauchshandlung dadurch initiiert worden war, dass sie von der Täterin bzw. dem Täter aufgefordert wurde, sich zu entkleiden, um ,untersucht“ zu werden. Aus dieser Schilderung geht hervor, dass die Täterin bzw. der Täter keine direkte physische Gewalt angewandt hatte, gleichzeitig ist eine „Mitschuld“ oder ein Verleiten im Sinne von Einvernehmlichkeit klar auszuschließen.

\section{Tathandlungen}

$\mathrm{Da}$ es sich beim sexuellen Kindesmissbrauch nicht um ein eindeutig umschriebenes Verhaltensmuster handelt, wurden die spezifischen Missbrauchshandlungen in Anlehnung an Wetzels (1997) anhand von 13 ausgewählten Antwortvorgaben und einer offenen Antwortoption „Sonstiges“ erfasst. In Kapitel 3 des vorliegenden Bandes (Fernau \& Hellmann, 2014) wurde die Definition sexuellen Missbrauchs durch katholische Geistliche, die im Rahmen dieser Studie angewandt wurde, bereits expliziert. Zusammengefasst wurden solche Personen als Betroffene von sexuellem Missbrauch durch katholische Geistliche kategorisiert, denen mindestens 
eine der 13 vorgegebenen sexuellen Handlungsformen mindestens einmal durch einen katholischen Geistlichen widerfahren war.

Die Straftat des sexuellen Missbrauchs reicht von leichteren Missbrauchsformen ohne Körperkontakt (z. B. Beobachten in Intimsituationen) über schweren Missbrauch (z. B. Berührungen im Genitalbereich) bis hin zu schwerstem Missbrauch (z. B. Penetration; Egle \& Abhary, 2005). Entsprechend wurde als Tatbestandteil unter anderem das Eindringen in die Intimsphäre der Betroffenen durch konkrete Fragen zur Sexualität oder durch Beobachtungen in intimen Momenten erfasst (siehe Abbildung 6). Außerdem wurde erfragt, ob die Täterin bzw. der Täter das Geschlechtsteil der bzw. des Geschädigten oral aufgenommen hatte. Falls die Betroffenen mit pornografischen Materialien konfrontiert worden waren, konnte auch diese Straftat in ihrer Häufigkeit angegeben werden. Des Weiteren wurde festgehalten, ob die Täterin bzw. der Täter vor den Betroffenen masturbiert hatte oder diese dazu aufgefordert hatte. Betroffene, welche die Täterin bzw. den Täter entkleiden mussten oder gedrängt worden waren, sich selbst zu entkleiden, konnten diese Erfahrung ebenfalls angeben. Für den Fall, dass die Betroffenen aufgefordert worden waren, die Täterin bzw. den Täter oder andere Kinder und Jugendliche sexuell zu berühren, wurde auch dieser Tatbestandteil erfasst. Die orale, anale bzw. vaginale Penetration mit Geschlechtsteilen, Körperteilen oder Gegenständen wurde ebenfalls aufgeführt. Falls die Betroffenen eine der vorgegebenen Missbrauchshandlungen erlebt hatten, wurden sie um eine Schätzung der Anzahl an Vorfällen gebeten. Darüber hinaus bestand die Möglichkeit, in einem zusätzlichen offenen Item (,Ein katholischer Geistlicher hat Folgendes gemacht:...") Missbrauchshandlungen zu benennen, die zuvor nicht angeführt worden waren. Die nachfolgend berichteten Daten basieren pro Antwortoption auf 92 bis 100 Angaben.

Insgesamt schilderten die Betroffenen am häufigsten, dass die Täterinnen bzw. Täter ihnen intime sexualisierte Fragen gestellt hatten. Diese Grenzüberschreitung war in $11.1 \%$ der Fälle einmalig erfolgt, während drei von fünf Befragten (60.6\%) angaben, mehrfach auf diese Art belästigt worden zu sein. $45.6 \%$ der Betroffenen berichteten zudem, in intimen Momenten beobachtet worden zu sein (7.6 \% einmalig; $38.0 \%$ mehrfach). Eine weitere Form des sexuellen Missbrauchs ohne Körperkontakt, die Konfrontation der Minderjährigen mit pornografischen Materialien, wurde insgesamt von mehr als jeder bzw. jedem fünften Betroffenen berichtet (7.0\% einmalig; $14.0 \%$ mehrfach). 


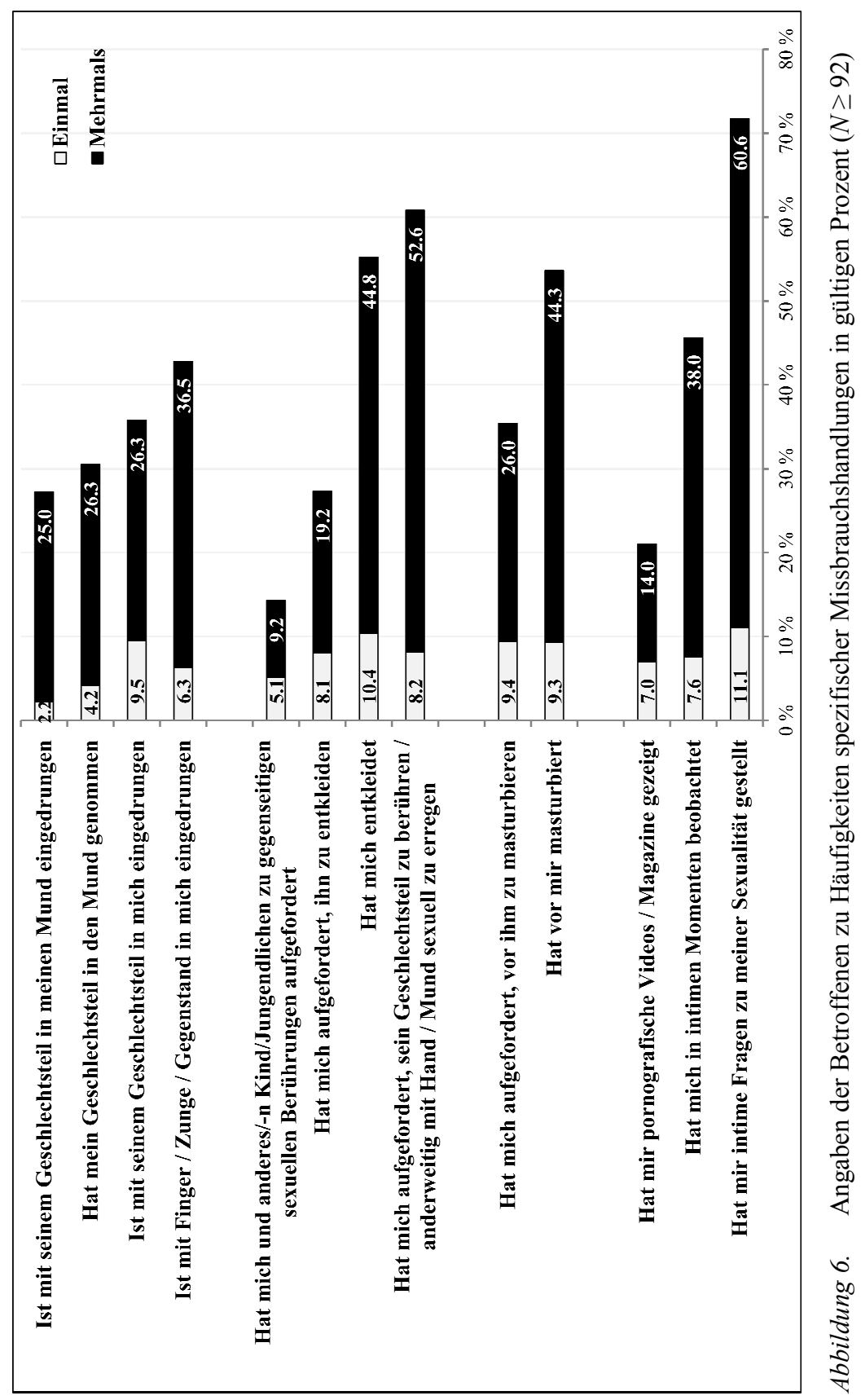


Vielfach waren die Betroffenen dazu aufgefordert worden, das Geschlechtsteil der Täterinnen bzw. Täter zu berühren oder diese anderweitig mit der Hand oder dem Mund sexuell zu erregen (60.8\%). Von $8.2 \%$ der Befragten wurde geschildert, mit dieser Aufforderung einmalig konfrontiert gewesen zu sein, weitere $52.6 \%$ der Befragten benannten diese Tathandlung als mehrfaches Vorkommnis. Deutlich mehr als die Hälfte der Geschädigten (55.2\%) waren von den Täterinnen bzw. Tätern teils einmalig (10.4\%), teils mehrfach (44.8\%) entkleidet worden. Zusätzlich berichteten $27.3 \%$ der Betroffenen, dass sie dazu aufgefordert worden waren, die beschuldigten Geistlichen $\mathrm{zu}$ entkleiden (8.1\% einmalig; $19.2 \%$ mehrfach). Wiederum in mehr als der Hälfte der Fälle (53.6 \%) hatten die Delinquentinnen bzw. Delinquenten vor den Betroffenen masturbiert (9.3\% einmalig, $44.3 \%$ mehrfach). Außerdem war mehr als ein Drittel der Geschädigten gezwungen worden, vor den Täterinnen bzw. Tätern zu masturbieren (9.4\% einmalig; $26.0 \%$ mehrfach). Penetrationen mit Fingern, Zunge oder Gegenständen wurden insgesamt von $42.8 \%$ der Betroffenen berichtet (6.3\% einmalig; $36.5 \%$ mehrfach). Mehr als ein Drittel der Betroffenen benannten die anale bzw. vaginale Penetration als Tathandlung ( $9.5 \%$ einmalig; $26.3 \%$ mehrfach).

Zusätzlich hatte rund jeder bzw. jede dritte Betroffene Oralverkehr, vollzogen durch die Täterinnen bzw. Täter, erlebt (4.2\% einmalig, $26.3 \%$ mehrfach). Die orale Penetration wurde von mehr als einem Viertel der Befragten geschildert (2.2\% einmalig; $25.0 \%$ mehrfach). Jede bzw. jeder siebte Geschädigte (5.1\% einmalig; 9.2\% mehrfach) gab zudem an, zu sexualisierten Handlungen mit anderen Minderjährigen aufgefordert worden zu sein.

Die Kategorie der sonstigen Missbrauchshandlungen bot Raum für weitere Tatbeschreibungen, die in den vorgegebenen Antwortoptionen nicht enthalten waren. Insgesamt erfolgten 67 Schilderungen individueller Missbrauchshandlungen, die unter anderem diverse Darstellungen sexualisierter Berührungen und Küsse sowie weiterer Missbrauchsformen beinhalteten.

Eine Betrachtung der Missbrauchshandlungen in Abhängigkeit vom Kontext des sexuellen Missbrauchs (institutionell vs. nicht-institutionell) ergab einige Auffälligkeiten. Zunächst ist festzuhalten, dass der Missbrauch durch katholische Geistliche innerhalb von Institutionen wie Heimen oder Internaten mit einer größeren Anzahl unterschiedlicher Missbrauchshandlungen einherging als der sexuelle Missbrauch durch katholische Geistliche, der außerhalb der genannten Institutionen stattfand, $t(102)=2.23, p=.028, d=0.44$. Im Mittel hatten diejenigen Betroffenen, 
die während des Missbrauchs in einem Internat oder einem Heim lebten, $M=6.24(S D=3.85)$ verschiedene der oben benannten Missbrauchshandlungen erlebt. Betroffenen, deren Lebensmittelpunkt sich zur Zeit des Missbrauchs nicht in einem Internat oder Heim befand, waren durchschnittlich $M=4.74(S D=2.98)$ unterschiedliche Missbrauchsformen widerfahren. Eine Fokussierung auf die körperlich schwersten Missbrauchsformen (aktive und passive orale, anale, vaginale oder digitale Penetration) ergab darüber hinaus, dass diese insgesamt häufiger von Betroffenen im institutionellen ( $v s$. nicht-institutionellen) Kontext erlebt worden waren. Auffällig war dabei, dass diese Unterschiede vor allem auf die Angaben derjenigen Betroffenen zurückzuführen waren, die innerhalb eines Heimkontexts viktimisiert worden waren (siehe Tabelle 6).

Tabelle 6. Angaben der Betroffenen zum Erleben körperlich schwerster Missbrauchsformen in Abhängigkeit vom Missbrauchskontext in gültigen Prozent $(N \geq 95)$

Missbrauchskontext

Teststatistiken

$\begin{array}{rrr}\text { Heim } & \text { Internat } & \begin{array}{r}\text { Nicht- } \\ (n \geq 24)\end{array} \\ & & \text { institutionell } \\ & & (n \geq 50)\end{array}$

\begin{tabular}{lrrrr}
\hline $\begin{array}{l}\text { Hat mein Geschlechts- } \\
\text { teil in den Mund } \\
\text { genommen }\end{array}$ & $\begin{array}{r}52.0 \% \\
(n=13)\end{array}$ & $\begin{array}{r}26.3 \% \\
(n=5)\end{array}$ & $\begin{array}{r}21.6 \% \\
(n=11)\end{array}$ & $\begin{array}{r}\chi^{2}(2, N=95)=7.52, \\
p=.023, \mathrm{CI}=.281\end{array}$ \\
$\begin{array}{l}\text { Ist mit seinem } \\
\begin{array}{l}\text { Geschlechtsteil in } \\
\text { meinen Mund }\end{array}\end{array}$ & $\begin{array}{r}54.2 \% \\
(n=13)\end{array}$ & $\begin{array}{l}16.7 \% \\
(n=3)\end{array}$ & $\begin{array}{r}18.0 \% \\
(n=9)\end{array}$ & $\begin{array}{r}\chi^{2}(2, N=92)=11.97, \\
p=.003, \mathrm{CI}=.361\end{array}$ \\
$\begin{array}{l}\text { eingedrungen } \\
\begin{array}{l}\text { Ist mit Finger / Zunge } \\
\text { Gegenstand in mich }\end{array}\end{array}$ & $\begin{array}{r}60.0 \% \\
\text { eingedrungen }\end{array}$ & $\begin{array}{l}36.8 \% \\
(n=15)\end{array}$ & $\begin{array}{r}36.5 \% \\
(n=19)\end{array}$ & $\chi^{2}(2, N=96)=4.13$, \\
$\begin{array}{l}\text { Ist mit seinem } \\
\begin{array}{l}\text { Geschlechtsteil in } \\
\text { mich eingedrungen }\end{array}\end{array}$ & $\begin{array}{r}59.3 \% \\
(n=16)\end{array}$ & $\begin{array}{r}27.8 \% \\
(n=5)\end{array}$ & $\begin{array}{r}26.0 \% \\
(n=13)\end{array}$ & $\begin{array}{r}\chi^{2}(2, N=95)=9.06, \\
p=.011, \mathrm{CI}=.309\end{array}$ \\
\hline
\end{tabular}

Anmerkungen. Die angegebenen Prozentwerte beziehen sich auf mindestens einmaliges Auftreten der jeweiligen Tathandlung.

Die absolute Zahl der insgesamt erlebten Missbrauchshandlungen unterschied sich hingegen weder in Abhängigkeit vom Geschlecht der Betroffenen, $t(63)<1$, noch in Abhängigkeit davon, ob der Missbrauch innerhalb einer Institution stattgefunden hatte oder nicht, $t(64)=1.10$, 
$p=.275$. Folglich waren betroffene Kinder und Jugendliche in einem institutionellen Kontext zwar einer größeren Anzahl unterschiedlicher Missbrauchsformen ausgesetzt als Betroffene, die zum Zeitpunkt des Missbrauchs nicht in einem institutionellen Kontext lebten. In der Summe unterschied sich die Anzahl der erlebten Missbrauchshandlungen jedoch nicht in Abhängigkeit vom Missbrauchskontext. Hierbei ist erneut darauf hinzuweisen, dass die geschilderten Vorfälle zum Teil sehr weit zurückliegen und eine Angabe zu der exakten Häufigkeit jeder einzelnen Missbrauchshandlung hier vermutlich nicht erwartet werden kann.

Multivariate Analysen ergaben, dass sowohl die Anzahl der unterschiedlichen erlebten Missbrauchshandlungen, $\beta=.361, p=.006$, als auch die Summe der insgesamt erlebten Missbrauchshandlungen, $\beta=.255$, $p=.048$, signifikante Prädiktoren für die Missbrauchsdauer waren, $R^{2}=.248, F(2,54)=8.56, p=.001 .^{7}$ Mit anderen Worten widerfuhren den Betroffenen mit steigender Missbrauchsdauer insgesamt mehr Missbrauchshandlungen und auch eine größere Anzahl an unterschiedlichen Viktimisierungen. Diverse andere potenzielle Prädiktoren (z. B. Betroffenengeschlecht, Erstviktimisierungsalter oder Missbrauchskontext) standen dabei in keinem direkten Zusammenhang mit der Missbrauchsdauer, alle $p>.156$.

\section{Drohungen}

Weiterhin war im vorliegenden Rahmen von Interesse, inwiefern die Betroffenen durch die Täterinnen bzw. Täter durch Drohungen dazu gebracht worden waren, nicht über den Missbrauch zu sprechen. Für acht potenziel-

Der Vorteil multivariater Analysen gegenüber bivariaten Analysen (z. B. Zusammenhang zwischen Missbrauchskontext und Missbrauchsdauer) besteht darin, dass der Einfluss mehrerer Variablen gleichzeitig untersucht werden kann. Im vorliegenden Fall handelt es sich um eine multivariate Regressionsanalyse. Damit läst sich feststellen, welche der betrachteten Prädiktoren (Vorhersagevariablen; hier z. B. Anzahl unterschiedlicher Missbrauchshandlungen und Summe der insgesamt erlebten Missbrauchshandlungen) mit dem Kriterium (gemessene / abhängige Variable; hier Missbrauchsdauer) zusammenhängen. Bei $\beta$ handelt es sich um den standardisierten Regressionskoeffizienten eines Prädiktors. Er kann Werte zwischen 0 und 1 annehmen und beinhaltet die Stärke des Zusammenhangs zwischen dem jeweiligen Prädiktor und dem Kriterium. $R^{2}$ ist ein Maß für die Effektstärke des gesamten Regressionsmodells. Dieses Maß variiert ebenfalls zwischen 0 und 1 und informiert über das Ausmaß der insgesamt aufgeklärten Varianz. Weiterführende Erläuterungen finden sich beispielsweise bei Bortz (2005). 
le Drohungen wurden die Betroffenen gebeten zu bewerten, ob diese in ihrem Fall völlig, teilweise oder gar nicht zutrafen (siehe Abbildung 7). Darüber hinaus konnten weitere „sonstige“ Drohungen im offenen Antwortformat beschrieben werden.

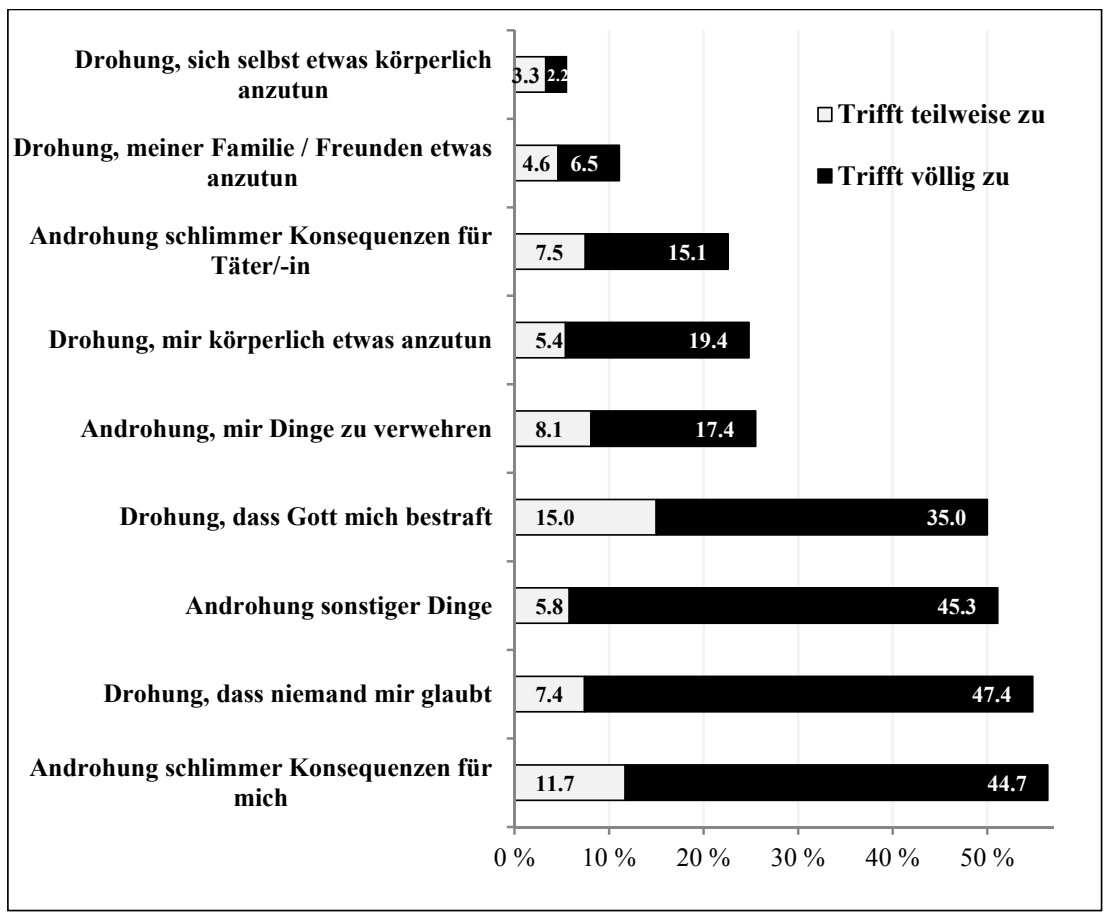

Abbildung 7. Angaben der Betroffenen zu Drohungen der beschuldigten Täterinnen bzw. Täter sexuellen Missbrauchs in gültigen Prozent $(N \geq 86)$

Insgesamt waren $77.5 \%$ der Betroffenen eigenen Angaben zufolge in irgendeiner Form bedroht worden, um sie davon abzuhalten, über die erlebte sexuelle Gewalt zu sprechen. Dies traf auf männliche $(74.7 \%)$ ebenso wie auf weibliche Betroffene zu (84.6\%), $\chi^{2}(1, N=101)=1.09, p=.297$. Betroffene, die zum Zeitpunkt des Missbrauchs in einem institutionellen Kontext gelebt hatten, waren insgesamt ebenso häufig bedroht worden, nicht über das Erlebte zu sprechen (83.7\%), wie Betroffene, die zur Zeit des Missbrauchs nicht in einem institutionellen Kontext gelebt hatten $(71.7 \%), \chi^{2}(1, N=102)=2.09, p=.148$. Allerdings ergab die genauere 
Betrachtung, dass vor allem Betroffene, denen der sexuelle Missbrauch im Rahmen eines Heimkontexts widerfahren war, bedroht worden waren (96.8 \%), während Betroffenen innerhalb eines Internatskontexts im Vergleich seltener gedroht worden war $(61.1 \%), \chi^{2}(1, N=49)=10.60$, $p=.001, \phi=.465$.

Die häufigsten Formen von Drohungen, nicht über den Missbrauch zu sprechen, betrafen das Androhen schlimmer Konsequenzen für die Betroffenen $(56.4 \%)$, die Drohung, dass ihnen niemand glauben würde (54.8 \%), die Androhung sonstiger Dinge (51.1\%) und die Drohung, dass Gott sie bestrafen würde (50.0\%). Dabei beinhalteten die "sonstigen“ Drohungen überwiegend Strafen mit religiösem Bezug (z. B. „Das[s] ich nach meinem Tod nicht durch die Himmelspforte in das Reich Gottes gelassen werde“; „Dass der Teufel die Familie holen wird“). In einem Viertel bzw. einem Fünftel der Fälle wurde angedroht, bestimmte Dinge zu verwehren (25.5\%), den Betroffenen körperlichen Schaden zuzufügen $(24.8 \%)$ oder dass der Täterin bzw. dem Täter schlimme Konsequenzen drohten, sollten die Betroffenen von dem Missbrauch erzählen (22.6\%). Deutlich seltener drohten die Täterinnen bzw. Täter damit, der Familie oder Freundinnen bzw. Freunden der Betroffenen etwas anzutun, falls diese über die erlebte sexuelle Gewalt sprächen (11.1\%), oder sich selbst etwas anzutun $(5.5 \%)$.

Hinsichtlich der verschiedenen Arten der Drohungen traten einige Unterschiede in Abhängigkeit vom Missbrauchskontext und dem Geschlecht der Betroffenen auf: Betroffenen, die zum Zeitpunkt des Missbrauchs in einem Heim gelebt hatten, wurde signifikant häufiger angedroht, dass ihnen nicht geglaubt würde, wenn sie über das Erlebte sprächen $(92.3 \%)$, im Vergleich $\mathrm{zu}$ Betroffenen, die innerhalb eines Internatskontexts $(29.4 \%)$ oder in einem außerinstitutionellen Kontext viktimisiert worden waren $(44.2 \%), \chi^{2}(2, N=95)=21.53, p<.001, \mathrm{CI}=.476$. Diese Androhung erlebten zudem weibliche Betroffene $(72.0 \%)$ häufiger als männliche Betroffene $(49.3 \%), \chi^{2}(1, N=94)=3.83, p=.050, \phi=.202$. Darüber hinaus wurden Betroffenen, die innerhalb eines Heimkontexts viktimisiert worden waren, häufiger ,schlimme Konsequenzen“, $\chi^{2}(2, N=94)=15.05$, $p<.001, \quad \mathrm{CI}=.413$, und körperliche Gewalt angedroht, $\chi^{2}(2, N=93)=13.38, p=.001, \mathrm{CI}=.379$, im Vergleich zu Betroffenen, die außerhalb eines institutionellen Kontexts oder im Rahmen eines Internatskontexts missbraucht worden waren (siehe Tabelle 7). 
Tabelle 7. Angaben der Betroffenen zu ausgewählten Drohungen für den Fall, dass sie über den Missbrauch sprachen, in Abhängigkeit vom Missbrauchskontext in gültigen Prozent $(N \geq 93)$

\begin{tabular}{lrrr}
\hline & \multicolumn{3}{c}{ Missbrauchskontext } \\
& $\begin{array}{r}\text { Heim } \\
(n \geq 26)\end{array}$ & $\begin{array}{r}\text { Internat } \\
(n \geq 17)\end{array}$ & $\begin{array}{r}\text { Nicht-institutionell } \\
(n \geq 50)\end{array}$ \\
\hline $\begin{array}{l}\text { Drohung, dass Betroffenen } \\
\text { nicht geglaubt wird }\end{array}$ & $\begin{array}{l}92.3 \% \\
(n=24)\end{array}$ & $\begin{array}{r}29.4 \% \\
(n=5)\end{array}$ & $\begin{array}{r}44.2 \% \\
(n=23)\end{array}$ \\
Androhung schlimmer & $88.0 \%$ & $29.4 \%$ & $50.0 \%$ \\
Konsequenzen für Betroffene & $(n=22)$ & $(n=5)$ & $(n=26)$ \\
Androhung körperlicher & $50.0 \%$ & $5.9 \%$ & $18.0 \%$ \\
Gewalt & $(n=13)$ & $(n=1)$ & $(n=1)$ \\
Androhung von Bestrafung & $65.5 \%$ & $33.3 \%$ & $45.3 \%$ \\
durch Gott & $(n=19)$ & $(n=6)$ & $(n=24)$ \\
\hline Anmerkungen. Din
\end{tabular}

Anmerkungen. Die angegebenen Prozentwerte beziehen sich auf die Betroffenenangaben ,trifft teilweise $z u^{\prime \prime}$ und ,,trifft völlig zu“.

Tendenziell erlebten diese Betroffenen häufiger die Drohung, dass Gott sie bestrafen würde, sollten sie über den Missbrauch sprechen (Heimkontext: $65.5 \%$, Internatskontext: $33.3 \%$, nicht-institutioneller Kontext: $45.3 \%)$. Dieser Unterschied erreichte jedoch keine statistische Signifikanz, $\chi^{2}(2, N=100)=5.23, p=.073$. Ein ebenfalls marginal signifikanter Unterschied ließ sich für die Drohung aufzeigen, dass der Familie oder Freundinnen bzw. Freunden der Betroffene etwas angetan würde, falls sie über den Missbrauch sprächen (weibliche Betroffene: $21.7 \%$, männliche Betroffene: $7.2 \%), \chi^{2}(1, N=92)=3.74, p=.053$. Darüber hinaus bestanden hinsichtlich der einzelnen Drohungen keine Unterschiede in Abhängigkeit vom Betroffenengeschlecht oder dem Missbrauchskontext, alle $p>.158$.

\section{Verbale und physische Gewalt}

Zusätzlich zu den im vorangegangenen Abschnitt berichteten sexuellen Gewalthandlungen wurde erfragt, welche Handlungen in Form von verbaler und physischer Gewalt die Täterinnen bzw. Täter gegen die Betroffenen verübt hatten (siehe Abbildung 8). Dabei sollten die Befragten alle zutreffenden Antwortoptionen markieren. Zudem konnten sie in der Kategorie „Sonstiges“ weitere Handlungen beschreiben, die zuvor nicht abgefragt 
worden waren. Da die Täterinnen bzw. Täter teilweise mehrere der beschriebenen Gewaltformen angewandt hatten, wurden insgesamt 160 Handlungen verbaler und physischer Gewalt erfasst.

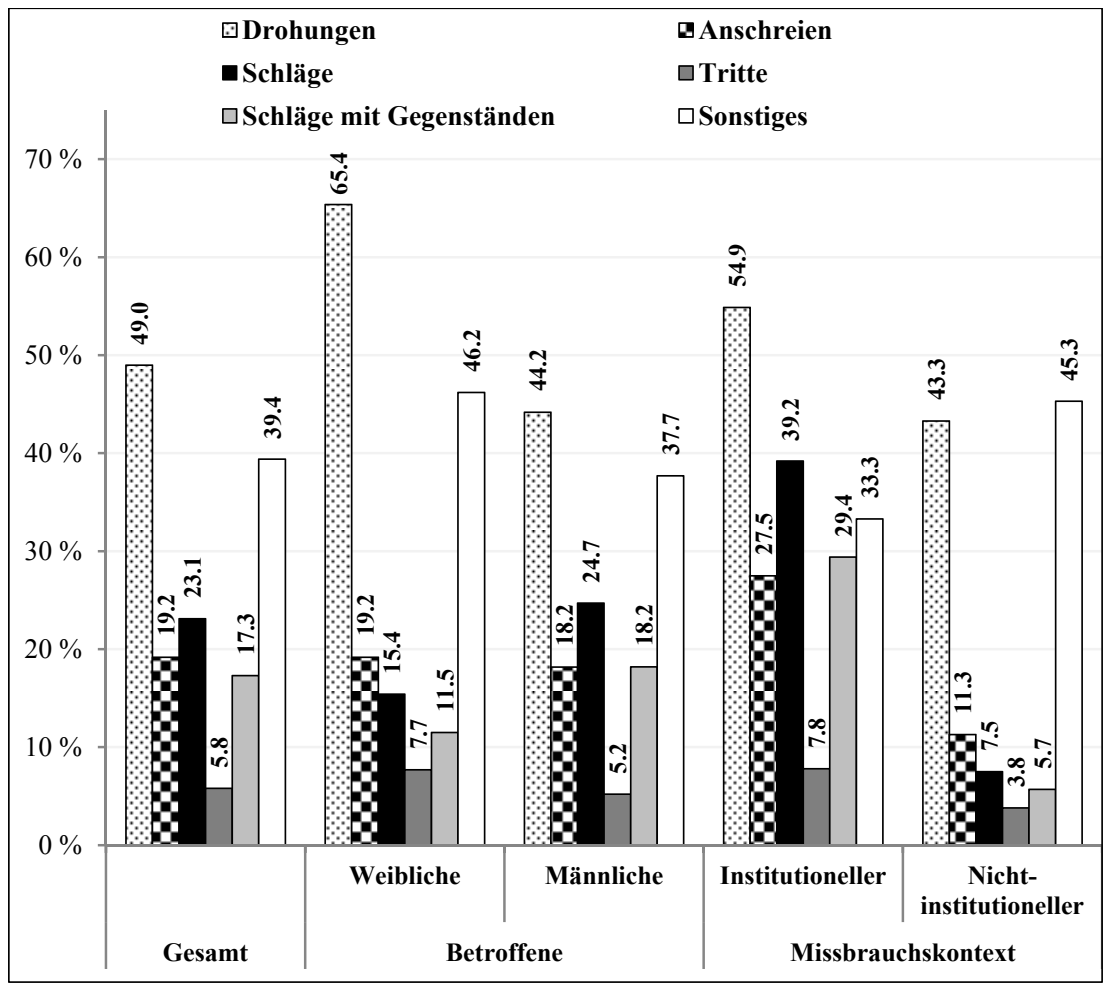

Abbildung 8. Angaben der Betroffenen zu verbalen und physischen Gewalthandlungen durch die beschuldigten Täterinnen bzw. Täter sexuellen Missbrauchs in gültigen Prozent (Mehrfachnennungen möglich; $N=104$ )

Am häufigsten äußerten die Geschädigten mit $49.0 \%$ insgesamt, dass ihnen von den Täterinnen bzw. Tätern gedroht worden war. Eine weitere Form der verbalen Gewalt, das Anschreien, hatten fast zwei von zehn Betroffenen erlebt (19.2\%). Physische Gewalt in Form von Schlägen teilten insgesamt $23.1 \%$ der Befragten mit. Diese Schläge waren in weiteren $17.3 \%$ der Fälle mit einem Gegenstand erfolgt. Zusätzlich war $5.8 \%$ der Betroffenen Gewalt in Form von Tritten angetan worden. 
Bezüglich des Geschlechts der Betroffenen zeigte sich lediglich ein (marginal) statistisch signifikanter Unterschied mit Blick auf die erfahrenen Drohungen, $\chi^{2}(1, N=103)=3.50, p=.061, \phi=.184$ : Weibliche Betroffene berichteten mit $65.4 \%$ tendenziell häufiger als die befragten männlichen Betroffenen (44.2\%), von den Täterinnen bzw. Tätern bedroht worden zu sein (alle anderen $p>.324$ ).

In Einklang mit den zuvor berichteten Ergebnissen zeigte eine Betrachtung des Missbrauchskontexts, dass den Betroffenen, die während des Missbrauchs in einem Internat oder Heim gelebt hatten, insgesamt mehr Gewalt durch die benannten Täterinnen bzw. Täter des sexuellen Missbrauchs widerfahren war als denjenigen Betroffenen, die zur Zeit des sexuellen Missbrauchs nicht in einer solchen Institution gelebt hatten: So wurden die institutionalisierten vs. nicht-institutionalisierten Geschädigten beispielsweise häufiger durch die Täterinnen bzw. Täter mit der Hand geschlagen $(39.2 \%$ vs. $7.5 \%)$, angeschrien $(27.5 \%$ vs. $11.3 \%)$ oder mit Gegenständen geschlagen $(29.4 \%$ vs. $5.7 \%)$, alle $\chi^{2}(1, N=104)>4.34$, alle $p<.038$, alle $\phi>.204$. Auffällig war wiederum, dass Betroffene, die innerhalb eines Heimkontexts viktimisiert worden waren, im Vergleich zu Betroffenen innerhalb eines Internatskontexts häufiger angeschrien $(38.7 \%$ vs. $10.0 \%), \chi^{2}(1, N=51)=5.03, p=.025, \phi=.314$, und mit Gegenständen misshandelt wurden $(41.9 \%$ vs. $10.0 \%), \chi^{2}(1, N=51)=5.97$, $p=.015, \phi=.342$. Aufgrund der geringen Zellbesetzungen sind diese Unterschiede allerdings mit Vorsicht zu interpretieren.

Fasst man die Betroffenenangaben zu verbaler und physischer Gewalt zu zwei Indizes zusammen, lässt sich festhalten, dass insgesamt mehr als die Hälfte der Betroffenen (52.9 \%) mindestens einmal psychische Gewalt in Form von Drohungen und Anschreien durch die Beschuldigten erlebt hatten. Dies traf besonders häufig auf Kinder und Jugendliche zu, die innerhalb eines Heimkontexts viktimisiert worden waren (Heimkontext: $71.0 \%$, Internatskontext: $40.0 \%$, nicht-institutioneller Kontext: $47.2 \%$ ), $\chi^{2}(2, N=104)=6.10, p=.047, C I=.242$. Insgesamt hatten $27.9 \%$ der Betroffenen eigenen Angaben zufolge mindestens eine Form der explizit erfassten Arten physischer Gewalt (Schlagen mit der Hand, Schlagen mit Gegenständen, Tritte) erlebt. Dies war wiederum besonders häufig im institutionellen Kontext (47.1\%) der Fall und traf vor allem auf Betroffene zu, die im Rahmen eines Heimkontexts sexuell missbraucht worden waren (Heimkontext: $58.1 \%$, Internatskontext: $30.0 \%$, nicht-institutioneller Kontext: $9.4 \%), \chi^{2}(2, N=104)=23.06, p<.001, \mathrm{CI}=.471$.

Besonders hervorzuheben sind darüber hinaus die Inhalte der 41 freien Einträge zu weiteren Gewalthandlungen (39.4\% der Betroffenen hatten 
die Frage nach Gewaltanwendungen durch die Täterinnen bzw. Täter mit Auswahl der Option „Sonstiges“ beantwortet): In sehr heterogenen Aussagen beschrieben die Geschädigten einerseits weitere Formen (angedrohter) physischer Gewalt und Freiheitsberaubung (z. B. „Ich mach dich tot“; "Ich wurde festgehalten und festgebunden“; „eingesperrt“). Andererseits schilderten sie unter anderem Beispiele von psychischer Gewalt durch Aufmerksamkeitsentzug (z. B. „Hat mich am nächsten Tag links liegen gelassen“), Isolation (z. B. „Er hat einen Keil zwischen mich und meine Eltern getrieben“) oder religiöse Drohungen (z. B. „Wenn ich nicht das tue, was er von mir erwartet, würde Gott mich nicht mehr lieb haben"; „Höllenstrafen angedroht, sollte ich das Schweigen brechen“). In diesen Aussagen klingen teilweise bereits die Versuche der Täterinnen bzw. Täter an, den Missbrauch in religiöse Handlungen einzubetten bzw. durch religiöse Handlungen zu rechtfertigen.

Zum Vergleich seien an dieser Stelle die Ergebnisse des Forschungsberichts der Universität Wien zum sexuellen Missbrauch durch katholische Geistliche in Österreich herangezogen: Lueger-Schuster (2012) erfasste ebenfalls Kombinationen von sexueller und psychischer bzw. physischer Gewalt. Am häufigsten (ca. $48 \%$ ) berichteten die befragten Betroffenen dort eine Kombination aller drei Gewaltformen: Etwa $30 \%$ der von sexuellem Missbrauch Betroffenen benannten in der österreichischen Befragung zusätzlich ausschließlich das Erleben psychischer Gewalt, $8 \%$ der Betroffenen gaben hingegen an, dass ihnen zusätzlich zum sexuellen Missbrauch ausschließlich physische Gewalt widerfahren war. Lediglich $14 \%$ der Befragten waren in dieser Studie ausschließlich von sexueller Gewalt durch katholische Geistliche betroffen und hatten darüber hinaus keinerlei physische oder psychische Gewalt erlebt.

\section{Religiöse Einbettung des Missbrauchs}

Die Frage „Hat der Täter die sexuelle Missbrauchshandlung in eine religiöse Handlung eingebettet?" bejahten in der vorliegenden Studie insgesamt 35.7 \% der Betroffenen. Die Häufigkeit der Nennung religiöser Einbettung war nicht abhängig vom Geschlecht der Betroffenen, $\chi^{2}(1, N=97)=1.35$, $p=.245$, oder davon, ob sich der Missbrauch in einem institutionellen $v s$. nicht-institutionellen Kontext ereignet hatte, $\chi^{2}(1, N=98)<1$. Von denjenigen Betroffenen, die berichteten, dass der Missbrauch in einen religiösen Kontext eingebunden worden war, wurden im offenen Antwortformat detailliertere Schilderungen erbeten. Die $n=35$ Beschreibungen beinhalteten 
insgesamt 47 Aspekte religiöser Handlungen. Diese ließen sich wiederum zu vier inhaltlichen Kategorien zusammenfassen:

1. Beichte / Seelsorge/ Sündenerlass / Teufelsaustreibung $(n=23$ Nennungen)

2. Missbrauchshandlungen auf Wunsch Gottes ( $n=9$ Nennungen)

3. Zeremonie / Segnung ( $n=8$ Nennungen)

4. Gebete / Bibellesung ( $n=3$ Nennungen)

Die übrigen vier Nennungen entsprachen inhaltlich keiner der genannten Kategorien und wurden daher der fünften Kategorie „Sonstiges“ zugeordnet. Um die Anonymität der Befragten weiterhin gewährleisten zu können, werden die konkreten Formen der religiösen Einbettungen bzw. Rechtfertigungen lediglich beispielhaft skizziert.

In die Kategorie Beichte / Seelsorge / Sündenerlass / Teufelsaustreibung fielen beispielsweise Aussagen wie „Sie warf mir vor, ein Heide zu sein und wollte wohl den Teufel vertreiben“ oder „Er erklärte, dass dies zur Beichte dazu gehört, wegen der Keuschheit". Diesem Bereich ließ sich mit $48.9 \%$ fast die Hälfte der benannten Aspekte zuordnen. Eine Nennung aus der Kategorie Missbrauchshandlungen auf Wunsch Gottes lautete zum Beispiel „Der liebe Gott will, dass die Frauen die Männer beglücken. Dafür sind die Frauen geschaffen. Darüber diskutiert man nicht. Du hast das so zu machen“. 19.1\% der Aussagen der Betroffenen fielen in diese Kategorie, weitere $17.0 \%$ der Nennungen wurden als Zeremonie / Segnung kategorisiert (z. B. ,Vergewaltigung mit Blick auf die Hostie in der Monstranz am Karsamstag“). Dem Bereich Gebete / Bibellesung (6.4\%) wurden Schilderungen wie „Ich sollte immer aus der Bibel vorlesen“ zugeordnet. Zu den $8.5 \%$ der ,sonstigen“ Nennungen zählte beispielsweise „Er wollte die Länge meines Penis“ messen, ob ich katholische Kinder zeugen könnte“.

\section{Zuwendungen und Privilegien}

Neben Drohungen und physischer bzw. verbaler Gewalt wurde von den Betroffenen erfragt, inwiefern sie vor, während oder nach dem sexuellen Missbrauch von der Täterin bzw. dem Täter in irgendeiner Form besondere Zuwendungen erhalten hatten (siehe Fernau \& Hellmann, 2014; Kap. 3 in diesem Band). Dabei bestand die Möglichkeit, für neun Items zu bewerten, ob sich die Täterin bzw. der Täter ihnen gegenüber entsprechend ver- 
halten hatte und wenn ja, in welchem konkreten Zeitraum dies der Fall gewesen war. Aus Gründen der Übersichtlichkeit wurden die Ergebnisse $\mathrm{zu}$ den unterschiedlichen Zeiträumen zusammengefasst, in denen die Betroffenen die entsprechenden Zuwendungen erhalten hatten (siehe Abbildung 9).

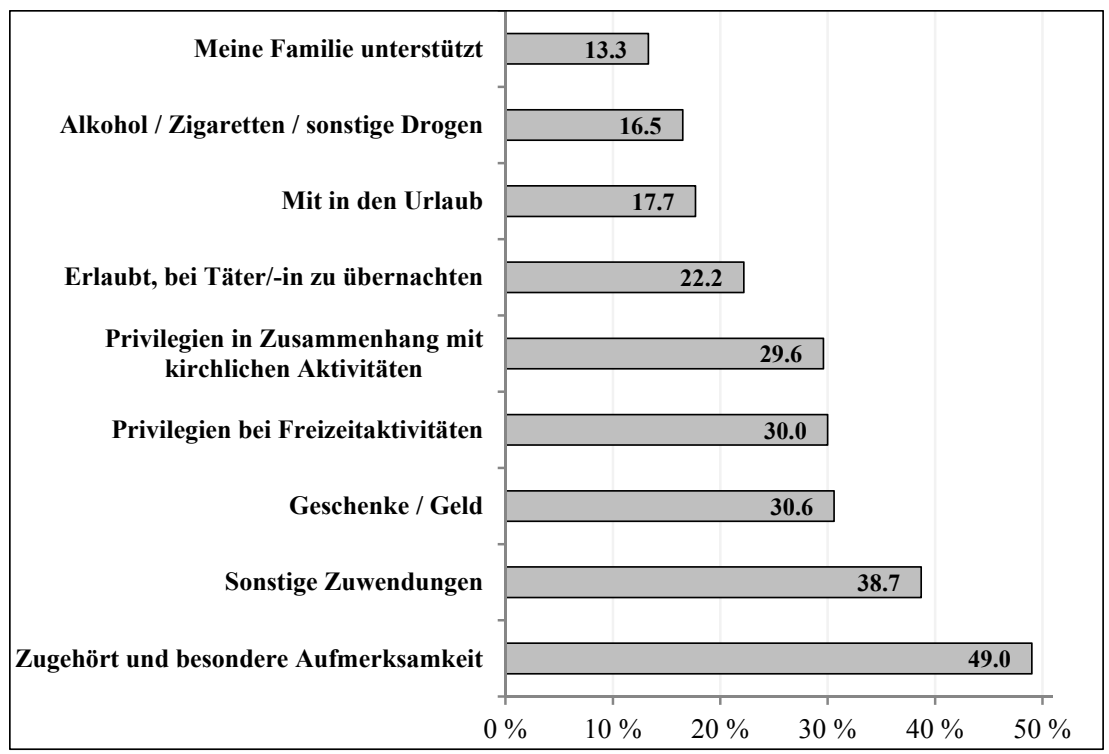

Abbildung 9. Angaben der Betroffenen zu Privilegien oder Zuwendungen, die sie in Zusammenhang mit dem sexuellen Missbrauch erhalten hatten, in gültigen Prozent (Mehrfachnennungen möglich; $N \geq 75$ )

Über alle Zeiträume und alle Antwortmöglichkeiten hinweg berichteten insgesamt $72.5 \%$ der Betroffenen, mindestens einmal eine Zuwendung bzw. ein Privileg in irgendeiner Form durch die Täterin bzw. den Täter erhalten zu haben. Das Ausmaß der benannten Zuwendungen hing dabei weder vom Betroffenengeschlecht noch davon ab, ob sich der Lebensmittelpunkt der Betroffenen zur Zeit des Missbrauchs in einem Heim oder Internat vs. nicht in einem Heim oder Internat befunden hatte, beide $p>.285$. Deskriptiv hatten männliche $(75.0 \%) v s$. weibliche Betroffene (64.0\%) sowie Betroffene, die außerhalb (76.9\%) vs. innerhalb (68.0\%) eines institutionellen Kontexts sexuelle Gewalt erlebt hatten, eigenen Angaben zufolge häufiger Privilegien oder besondere Zuwendungen erhalten. 
Die Berichte der Betroffenen zu den einzelnen Zuwendungsformen betrafen am häufigsten das Zuhören und Zukommenlassen besonderer Aufmerksamkeit durch die Täterin bzw. den Täter. Dass mit 49.0 \% knapp die Hälfte der Betroffenen diese Form der Zuwendung durch die missbrauchende Person benannte, lässt sich als Hinweis darauf deuten, dass sie ein besonderes Bedürfnis nach elterlicher Liebe und Zuwendung hatten, welches sich die Missbrauchstäterinnen und -täter bei der Durchsetzung ihrer Tat(en) möglicherweise zunutze gemacht haben. Die zweithäufigste Nennung (38.7 \%) in diesem Zusammenhang betraf ,sonstige Zuwendungen“. Diesbezüglich beschrieben die Betroffenen im offenen Antwortformat neben religiösen Aspekten (z. B. ,er hat die Rettung meiner Seele versprochen“) vor allem besondere Erlebnisse (z. B. „Autofahrten, Schwimmbadbesuche“; „nahm mich mit zum Baden“). Ungefähr je drei von zehn Betroffenen berichteten von Geschenken oder Geld (30.6\%), Privilegien bei Freizeitaktivitäten $(30.0 \%)$ und Privilegien in Zusammenhang mit kirchlichen Aktivitäten (29.6\%). Konkret wurden als privilegierte kirchliche Aktivitäten beispielsweise das Übernehmen besonderer Führungsaufgaben oder spezieller liturgischer Aufgaben benannt. 22.2\% der Betroffenen wurde erlaubt, bei der Täterin bzw. dem Täter zu übernachten. In rund jedem sechsten Fall erhielten die Betroffenen eigenen Angaben zufolge das Privileg, die Täterin bzw. den Täter in den Urlaub zu begleiten (17.7\%), bzw. Zuwendungen in Form von Alkohol, Zigaretten oder sonstigen Drogen (16.6\%). Die mit $13.3 \%$ am seltensten benannte Form der Zuwendung bestand darin, dass die Täterin bzw. der Täter die Familie der Betroffenen unterstützt hatte.

Die Betrachtung der einzelnen erfragten Aufmerksamkeiten ergab keine statistisch signifikanten Unterschiede in Abhängigkeit vom Betroffenengeschlecht, alle $p>$.117. Stattdessen zeigte sich, dass Betroffene, die außerhalb eines institutionellen Kontexts missbraucht worden waren, signifikant häufiger von Privilegien in Zusammenhang mit kirchlichen Aktivitäten (39.2\% vs. 19.1\%), Zuhören und besondere Aufmerksamkeit (62.7 \% vs. $34.0 \%)$ sowie gemeinsamem Urlaub mit der Täterin bzw. dem Täter (26.5\% vs. $8.5 \%$ ) berichteten als Betroffene, die zum Missbrauchszeitpunkt in einem institutionellen Kontext gelebt hatten, alle $\chi^{2}(1, N \geq 96)>4.72$, alle $p<.031$, alle $\phi>.219$. 


\section{Alkohol- und Drogeneinfluss, Anfertigung pornografischen Materials}

Weiterhin war im vorliegenden Rahmen von Interesse, inwiefern die Betroffenen oder Täterinnen bzw. Täter während der sexuellen Missbrauchshandlungen unter Alkohol- oder Drogeneinfluss gestanden hatten und ob pornografisches Material des Missbrauchs in Form von Fotos oder Videos erstellt worden war. Dazu wurde zum einen gefragt „Standen Sie bzw. der Täter während der sexuellen Missbrauchshandlung unter Alkohol- oder Drogeneinfluss?“ und zum anderen „Wurden im Zusammenhang mit einer Missbrauchshandlung Fotos oder Videos angefertigt?“"

Mit insgesamt $72.8 \%$ berichtete der Großteil der Betroffenen, dass weder sie noch die Täterin bzw. der Täter zur Tatzeit unter Alkohol- oder Drogeneinfluss gestanden hatten. 5.8\% der Betroffenen hatten eigenen Angaben zufolge während mindestens einer Missbrauchshandlung unter Alkohol- oder Drogeneinfluss gestanden. Mehr als jede bzw. jeder achte Betroffene gab hingegen an, dass ausschließlich die Täterinnen bzw. Täter mindestens einmal unter Alkohol- oder Drogeneinfluss agiert hatten (11.7\%). 9.7\% der Befragten berichteten, dass neben den Delinquentinnen bzw. Delinquenten auch sie selbst zu mindestens einem Tatzeitpunkt unter dem Einfluss von Alkohol oder Drogen gestanden hatten. Diese Daten entsprechen weitestgehend den Ergebnissen des Forscherteams des John Jay College (2004): Dort wurde ebenfalls berichtet, dass mehrheitlich weder die Betroffenen selbst (84.9\%) noch die Täterinnen bzw. Täter (78.4 \%) während der sexuellen Missbrauchshandlung unter Alkohol- oder Drogeneinfluss gestanden hatten.

Eine Betrachtung dieser Angaben in Abhängigkeit vom Geschlecht der Betroffenen, $\chi^{2}(3, N=102)=6.06, p=.109$, und ihrem Lebensmittelpunkt zum Zeitpunkt des sexuellen Missbrauchs (institutionell vs. nichtinstitutionell), $\chi^{2}(3, N=103)=4.00, p=.262$, ergab keine statistisch bedeutsamen Unterschiede. Unter Umständen ist dies jedoch auf die teilweise sehr geringen Fallzahlen zurückzuführen. Deskriptiv zeigte sich zum Beispiel, dass weibliche Betroffene (15.4\%) und Betroffene, die zum Missbrauchszeitpunkt in einem Internat oder Heim gelebt hatten (10.0\%), häufiger als männliche (2.6\%) und Betroffene, die während des Missbrauchs nicht in einer derartigen Institution gelebt hatten (1.9\%), berichteten, zu mindestens einem Tatzeitpunkt durch Alkohol oder Drogen beeinflusst gewesen zu sein.

Insgesamt berichtete ungefähr jede bzw. jeder achte Befragte, dass die Täterinnen bzw. Täter (10.7 \%) oder andere Personen (1.9 \%) Fotos oder Videos des sexuellen Missbrauchs angefertigt hatten. Fast zwei Drittel der 
Betroffenen $(64.1 \%)$ waren sich sicher, dass die Tat(en) weder gefilmt noch fotografiert worden waren. Knapp ein Viertel der Betroffenen (23.3 \%) hatte hingegen keine Kenntnis davon, ob überhaupt Aufnahmen von einer oder mehreren Missbrauchshandlungen erstellt worden waren. Die KFN-Befragung zu sexuellem Missbrauch im Allgemeinen kam diesbezüglich zu vergleichbaren Ergebnissen: Dort berichteten $90.5 \%$ der Betroffenen, dass von dem Missbrauch kein pornografisches Material angefertigt worden war, während $7.7 \%$ keine gesicherten Angaben zu potenziellen Film- oder Fotoaufnahmen machen konnten (Stadler et al., 2012). $1.7 \%$ der dort befragten Betroffenen konnten mit Sicherheit sagen, dass von dem Missbrauch pornografisches Film- oder Fotomaterial erstellt worden war.

Abhängigkeiten der Angaben zur Anfertigung pornografischen Materials vom Geschlecht der Betroffenen, $\chi^{2}(3, N=102)=6.25, p=.100$, oder ihrem Lebensmittelpunkt zum Zeitpunkt des sexuellen Missbrauchs (institutionell $v s$. nicht-institutionell), $\chi^{2}(3, N=103)=2.08, p=.556$, ließen sich in der vorliegenden Studie wiederum nicht nachweisen. Erneut muss jedoch darauf hingewiesen werden, dass es sich bei den analysierten Fällen teilweise um sehr kleine Zellbesetzungen handelt und möglicherweise aus diesem Grund keine signifikanten Effekte aufgezeigt werden konnten. Auffällig war beispielsweise, dass insgesamt in $14.3 \%$ der Fälle mit männlichen Betroffenen pornografisches Material erstellt worden war, während dies nur bei 4.0 \% der weiblichen Betroffenen eigenen Angaben zufolge der Fall gewesen war. Im Gegensatz dazu hatten in der Befragung von Stadler et al. (2012) ausschließlich weibliche Betroffene angegeben, dass sie sich sicher waren, dass von dem sexuellen Missbrauch pornografische Fotos oder Videos angefertigt worden waren.

\section{II.4 Wie hat der Missbrauch aufgehört?}

Im Folgenden wird berichtet, welche Personengruppen von dem sexuellen Missbrauch Kenntnis hatten und was zur Beendigung des Missbrauchs geführt hatte. Zunächst wurden die Betroffenen dazu gebeten zu beantworten, ob jemand zu der Zeit des sexuellen Missbrauchs von dem Verhalten der Täterin bzw. des Täters gewusst hatte. Dabei ging es nicht in erster Linie darum, ob sich die Betroffenen aktiv einer anderen Person anvertraut hatten (siehe dazu Wollinger, Dinkelborg \& Baier, 2014; Kap. 7 in diesem Band), sondern vor allem um Mitwisserinnen und Mitwisser, die auf anderen Wegen von dem Missbrauch erfahren hatten. Die Befragten wurden 
gebeten, aus allen präsentierten Antwortoptionen die zutreffende(n) auszuwählen (siehe Abbildung 10). Die offene Antwortkategorie ,sonstige Person" bot wiederum Raum für die Benennung weiterer Personen bzw. Personengruppen. Aufgrund der Möglichkeit von Mehrfachnennungen wurden insgesamt 206 gültige Antworten generiert.

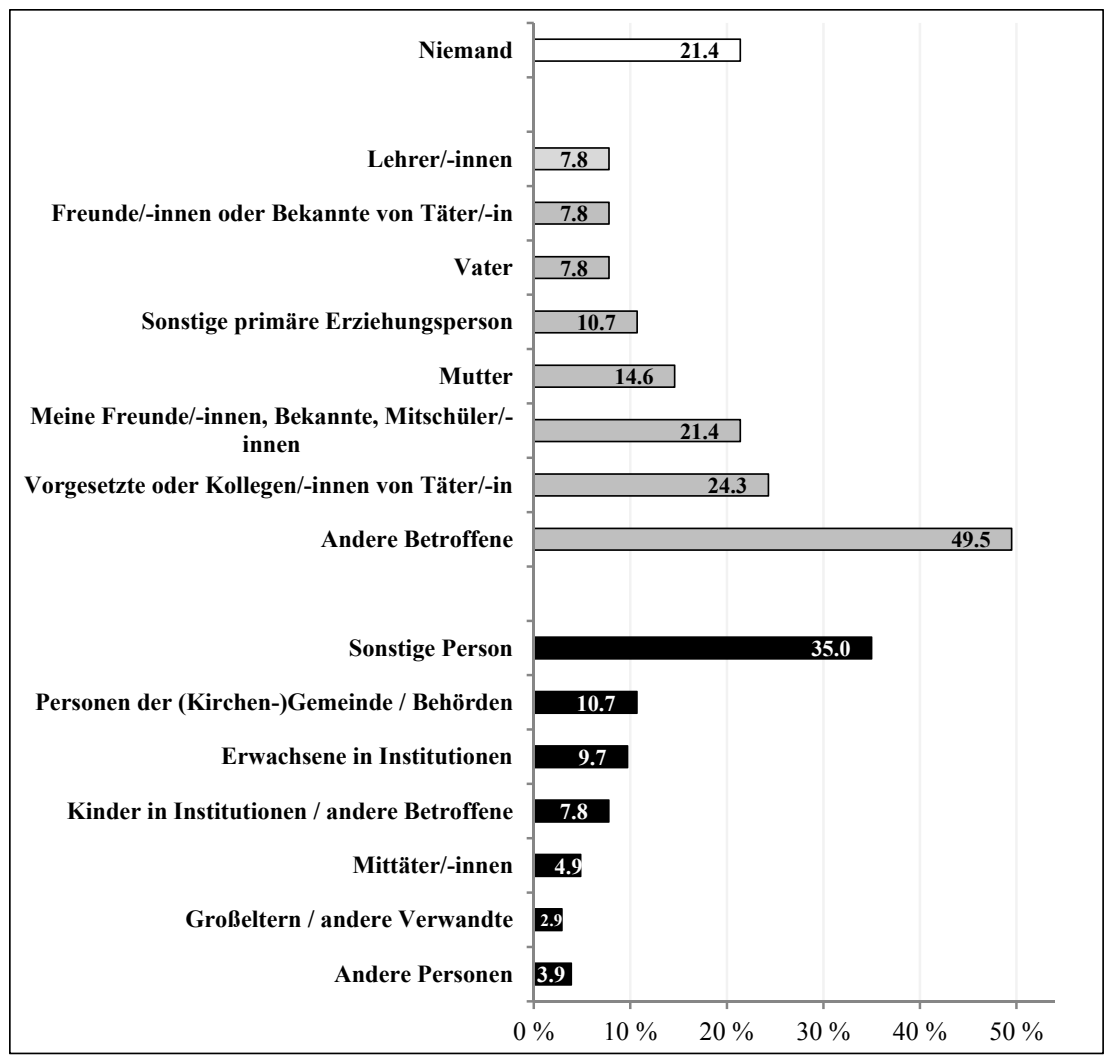

Abbildung 10. Angaben der Betroffenen zu Personen, die zur Zeit des sexuellen Missbrauchs Kenntnis davon hatten, in gültigen Prozent (Mehrfachnennungen möglich; $N=104$ )

Mehrheitlich (78.6\%) indizierten die Antworten der Betroffenen, dass es bereits zum Tatzeitpunkt andere Personen gab, die von dem Verhalten der Täterinnen bzw. Täter Kenntnis hatten. Tendenziell traf dies häufiger auf diejenigen Betroffenen $\mathrm{zu}$, die innerhalb eines institutionellen Kontexts viktimisiert worden waren $(86.0 \%)$, im Vergleich zu denjenigen, denen 
der sexuelle Missbrauch außerhalb eines institutionellen Kontexts widerfahren war $(71.7 \%), \chi^{2}(1, N=103)=3.13, p=.077$. Dieser tendenzielle Unterschied war vor allem auf die häufigen Nennungen anderer Betroffener zurückzuführen, die von dem Missbrauch gewusst hatten: Missbrauchstaten, die im institutionellen Kontext stattgefunden hatten, waren anderen Betroffenen zu $62.0 \%$ bekannt. Von den vorliegend erfassten Missbrauchstaten, die sich im nicht-institutionellen Kontext ereignet hatten, wussten andere Betroffene zum Missbrauchszeitpunkt hingegen nur zu $37.7 \%, \chi^{2}(1, N=103)=6.06, p=.014, \phi=.243$.

Ebenso hatten den Angaben der Betroffenen zufolge Freundinnen bzw. Freunde, Bekannte und Mitschülerinnen bzw. Mitschüler häufiger von sexuellem Missbrauch im institutionellen Kontext Kenntnis (32.0\%) als von sexuellem Missbrauch im außerinstitutionellen Kontext (11.3\%), $\chi^{2}(1, N=103)=6.55, p=.010, \phi=.252$. Insgesamt wurden in etwa einem Fünftel der Fälle (21.4 \%) Freundinnen bzw. Freunde, Bekannte oder Mitschülerinnen bzw. Mitschüler als Mitwissende benannt.

Mit 14.6\% wussten Mütter der Geschädigten deren Angaben zufolge deskriptiv häufiger über die Handlungen der Täterinnen bzw. Täter Bescheid als sonstige primäre Erziehungspersonen (10.7\%) und Väter (7.8\%). Diese Nennungen waren wiederum abhängig vom Missbrauchskontext: Betroffene, die zum Zeitpunkt der Viktimisierung in einem institutionellen Kontext gelebt hatten, berichteten signifikant seltener $(6.0 \%)$, dass ihre Mutter Kenntnis davon gehabt hätte, als Betroffene, die zum Missbrauchszeitpunkt nicht in einer Institution gelebt hatten $(22.6 \%)$, $\chi^{2}(1, N=103)=5.73, p=.017, \phi=.236$. Deskriptiv ließ sich dieser Unterschied auch für die Väter abbilden (4.0\%vs. $11.3 \%)$, er erreichte allerdings keine statistische Signifikanz, $\chi^{2}(1, N=103)=1.93, p=.165$. Dass sonstige primäre Erziehungspersonen von Betroffenen aus dem institutionellen Kontext häufiger (20.0\%) als Mitwissende benannt wurden im Vergleich zu Betroffenen aus dem außerinstitutionellen Kontext (1.9\%), $\chi^{2}(1, N=103)=8.85, p=.003, \phi=.293$, ist vor allem auf die Angaben der damaligen Heimkinder zurückzuführen (Heimkontext: $33.3 \%$; Internatskontext: $0 \%$ ).

Ungefähr ein Viertel (24.3\%) der betroffenen Personen gab an, dass Vorgesetzte oder Kolleginnen bzw. Kollegen der Delinquentinnen bzw. Delinquenten über deren Handeln informiert gewesen waren. Freundinnen bzw. Freunde oder Bekannte der Delinquentinnen bzw. Delinquenten sowie Lehrerinnen bzw. Lehrer waren jeweils vergleichsweise selten über die sexuellen Missbrauchshandlungen informiert (jeweils $7.8 \%$ ). Unter- 
schiede in Abhängigkeit vom Missbrauchskontext traten diesbezüglich nicht auf, alle $p>.514$.

Die Option ,sonstige Person“ wurde von $n=36$ Befragten zur Beantwortung der Frage nach Mitwisserinnen bzw. Mitwissern gewählt (35.0\%). Aus deren Antworten wurden 41 Aspekte generiert, die in sechs Kategorien zusammengefasst werden konnten. Bezogen auf alle 206 gültigen Angaben berichteten $10.7 \%$ der Betroffenen, Menschen aus der Kirchengemeinde (z. B. ,eine Familie in seiner Pfarrei“) bzw. der Stadt (z. B. „die ganze Stadt?") oder Behörden (z. B. „Jugendamt") hätten zu der Zeit des Missbrauchs davon gewusst (siehe Abbildung 10). 9.7\% der Nennungen bezogen sich auf Erwachsene innerhalb der Institution, in welcher der Missbrauch stattgefunden hatte (z. B. „Internatsleiter und Ordensoberer"). Die Befragten benannten zu $7.8 \%$ (andere betroffene) Kinder aus derselben Institution, in welcher der sexuelle Missbrauch erlebt worden war (z. B. „Heimkinder, die er ebenfalls zu sich holte“ oder ,andere Heimkinder"). In etwa jedem zwanzigsten Fall (4.9 \%) wussten Mittäterinnen bzw. Mittäter von dem sexuellen Missbrauch (z. B. „der fotografierende Diakon") und in $2.9 \%$ der Fälle wurden Großeltern oder andere Verwandte als sonstige Personen benannt, die von den Taten der Delinquentinnen bzw. Delinquenten wussten. $3.9 \%$ der von den Betroffenen als Mitwisserinnen bzw. Mitwisser benannten sonstigen Personen wurden wiederum der Kategorie ,andere Personen“ zugeordnet. Hierbei handelte es sich beispielsweise um uneindeutige Angaben oder solche Personen, die sich keiner der bestehenden Kategorien unterordnen ließen (z. B. „Haushälterin des Pfarrers").

Festzuhalten ist mit Blick auf die Angaben der Betroffenen zu Personen, die Kenntnis von dem Missbrauch hatten, dass es sich hier einerseits um aktives Hilfesuchverhalten der Betroffenen selbst handelte, das teilweise auf große Widerstände bei den Adressatinnen und Adressaten stieß (siehe dazu auch Wollinger et al., 2014; Kap. 7 in diesem Band). Andererseits wurden die Betroffenen jedoch auch direkt von Außenstehenden angesprochen. Dies wurde vor allem in den teilweise ausführlichen Schilderungen im offenen Antwortformat zu den ,sonstigen“ Personen deutlich. Abschließend ist anzumerken, dass der Term „Mitwisserinnen und Mitwisser" in diesem Zusammenhang nicht wertend zu verstehen ist.

Um zu erfahren, wodurch die Beendigung des sexuellen Missbrauchs initiiert worden war, wurden den Befragten diverse Gründe offeriert. Die Ursachen einer Beendigung durch Verhaltensänderungen bzw. aktive Maßnahmen der Betroffenen umfassten die Antwortoptionen „Ich habe jemandem davon erzählt und die Person hat dafür gesorgt, dass es auf- 
hört", „Ich bin weggezogen“" und „Ich habe es beendet". Täterspezifische Ursachen hingegen beschrieben die Antwortvorgaben „Der Täter hat sich einem anderen Missbrauchsopfer zugewandt“, „Der Täter zog weg“, „Der Täter verstarb“ und „Der Täter wurde versetzt". Zusätzlich stand die Antwortoption „Es hat einfach aufgehört“ zur Verfügung. Falls keiner der genannten Gründe zutreffend war, bestand die Möglichkeit, unter „Sonstiges" die individuelle Ursache für das Ende des Missbrauchs zu erläutern.

Tabelle 8. Antworten der Betroffenen auf die Frage „Wie endete der sexuelle Missbrauch?" und kategorisierte offene Angaben der Betroffenen zu „sonstigen“ Beendigungen des sexuellen Missbrauchs in gültigen Prozent $(N=104)$

\begin{tabular}{lr}
\hline „Ich habe jemanden davon erzählt und die Person hat dafür gesorgt, & $9.6 \%$ \\
dass es aufhört“ & $10.6 \%$ \\
„Ich bin weggezogen“ & $15.4 \%$ \\
„Ich habe es beendet“ & $3.9 \%$ \\
„Der Täter zog weg oder verstarb“ & $9.6 \%$ \\
„Der Täter hat sich einem anderen Missbrauchsopfer zugewandt“ & $12.5 \%$ \\
"Der Täter wurde versetzt“ & $7.7 \%$ \\
„Es hat einfach aufgehört“ & $30.8 \%$ \\
Sonstiges & $11.5 \%$ \\
Flucht / anderweitiger Entzug vor dem Zugriff der Täter/-innen & $10.6 \%$ \\
Reguläres Ende von institutionellem Aufenthalt & $4.8 \%$ \\
Aufnahme in ein (anderes) Heim & $2.9 \%$ \\
Umzug / Versetzung Täter/-in & $1.9 \%$ \\
Einmaliger Vorfall & $1.9 \%$ \\
Andere Gründe &
\end{tabular}

Ebendiese freie Kategorie „Sonstiges“ wurde mit insgesamt $30.8 \%$ am häufigsten genutzt (siehe Tabelle 8). Die von $n=32$ Personen benannten 35 unterschiedlichen Aspekte konnten in sechs Bereiche eingeteilt werden. Bezogen auf die insgesamt benannten Gründe für das Ende des sexuellen Missbrauchs $(N=104)$ wurde die Beendigung zu $1.9 \%$ dadurch begründet, dass es sich um einmalige Vorfälle gehandelt hatte und nach $2.9 \%$ aller Aussagen dadurch, dass die Täterin bzw. der Täter umgezogen oder 
versetzt worden war. Jeweils ungefähr jede zehnte Angabe bezog sich auf Beendigungen des Missbrauchs durch das reguläre Ende eines Internats-, Heim- oder sonstigen institutionellen Aufenthalts (10.6\%) bzw. die Flucht aus einer solchen Institution oder anderweitiges Entziehen von dem Zugriff der Täterin bzw. des Täters (11.5\%). In $4.8 \%$ der Fälle beschrieben die Betroffenen, dass sie in ein anderes Heim versetzt bzw. überhaupt in ein Heim aufgenommen worden waren. In die Kategorie „Andere Gründe" fielen wiederum Aspekte, die sich keinem der zuvor genannten Bereiche zuordnen ließen (1.9\%; z. B. „Ich habe ihn gebeten, den Missbrauch zu beenden").

Darüber hinaus wurden als Gründe für die Initiierung des Endes der Missbrauchshandlungen zu ungefähr gleichen Teilen die Optionen „Ich habe es beendet“ (15.4\%), „Der Täter wurde versetzt“ (12.5\%) und „Ich bin weggezogen“" $(10.6 \%)$ benannt. In rund jedem zehnten Fall endete der sexuelle Missbrauch den Angaben der Betroffenen zufolge dadurch, dass die Täterin bzw. der Täter sich einem anderen Kind bzw. Jugendlichen zuwandte $(9.6 \%)$ oder die Betroffenen sich einer anderen Person anvertrauten, die daraufhin das Ende des Missbrauchs einleitete (9.6\%). Verhältnismäßig selten kam der sexuelle Missbrauch zu einem Ende, weil die Täterinnen bzw. Täter wegzogen $(2.9 \%)$ oder verstarben $(1.0 \%)$. Ungefähr jeder dreizehnte Fall endete ohne aktives Zutun von außen oder den Betroffenen selbst (7.7\%).

Eine einzelne Betrachtung der unterschiedlichen Gründe für das Ende des sexuellen Missbrauchs ergab weder Abhängigkeiten vom Geschlecht der Betroffenen, $\chi^{2}(8, N=103)=8.46, p=.390$, noch davon, ob die Betroffenen zum Zeitpunkt des Missbrauchs in einem institutionellen Kontext gelebt hatten oder nicht, $\chi^{2}(8, N=104)=12.36, p=.136$. Aufgrund der verhältnismäßig großen Anzahl betrachteter Kategorien ist dies jedoch wenig überraschend.

\section{Fazit}

Der vorliegende Beitrag hatte zum Ziel, einen Überblick über die zentralen Ergebnisse zu den spezifischen Merkmalen erlebten sexuellen Missbrauchs durch katholische Geistliche in Deutschland zu geben, die im Rahmen der KFN-Betroffenenbefragung gewonnen wurden. Im Mittelpunkt standen dabei zum einen die spezifischen Charakteristika der Täterinnen und Täter sowie charakteristische Merkmale der Betroffenen. Zum 
anderen waren die konkreten Tathandlungen und ihr Kontext sowie das Ende des sexuellen Missbrauchs von Interesse.

Insgesamt zeigte sich vor allem hinsichtlich der konkreten Umstände des Missbrauchs, dass eine Quantifizierung des Erlebten dem heterogenen Tatgeschehen nicht immer vollständig gerecht werden konnte (z. B. bezüglich der Beendigung des Missbrauchs oder der Angaben der Betroffenen zu den Häufigkeiten spezifischer Missbrauchshandlungen). Gleichzeitig beantworteten die Betroffenen teilweise Fragen zu einzelnen Tatmerkmalen überaus homogen, sodass hier eine Quantifizierung angebracht war (z. B. hinsichtlich des Lebensmittelpunkts zur Zeit des Missbrauchs). Zudem eignete sich eine Quantifizierung der Betroffenenangaben insofern, als konkrete Merkmale des erlebten Missbrauchs häufig von einem institutionellen $v s$. nicht-institutionellen Kontext bzw. dem Geschlecht der Befragten abhängig waren (z. B. Viktimisierungsalter oder Tatzeitraum). Die dokumentierten Befunde bestätigten überwiegend die Ergebnisse vergleichbarer Betroffenenbefragungen zum sexuellen Missbrauch im Allgemeinen (z. B. Stadler et al., 2012) bzw. zum sexuellen Missbrauch durch katholische Geistliche im Speziellen (z. B. John Jay College, 2004; Lueger-Schuster, 2012).

\section{III.1 Zusammenfassung der Ergebnisse}

Zum Zeitpunkt der Erstviktimisierung hatten die Betroffenen ein mittleres Alter von knapp elf Jahren. Durchschnittlich dauerte der sexuelle Missbrauch drei Jahre, sodass das Alter der Betroffenen bei der letzten Viktimisierung im Mittel 14 Jahre betrug. Auffällig war, dass fast jeder zweite Vorfall sexueller Gewaltviktimisierungen durch katholische Geistliche in einem institutionellen Kontext (Heime, Internate) stattgefunden hatte. Vor allem traf dies auf männliche Befragte zu. Das Alter zum Zeitpunkt der letzten Viktimisierung war bei denjenigen Betroffenen höher, die währenddessen in einem institutionellen Kontext gelebt hatten, im Vergleich zu Betroffenen, die zum Zeitpunkt des sexuellen Missbrauchs nicht in einem institutionellen Kontext gelebt hatten. Innerhalb des institutionellen Missbrauchskontexts wurden Betroffene in Heimen früher in ihrem Leben und über einen längeren Zeitraum viktimisiert als Betroffene in Internaten.

Der Wohnort der Betroffenen zur Zeit des Missbrauchs war mehrheitlich durch Katholikinnen und Katholiken geprägt und wies in mehr als der Hälfte der Fälle eine Einwohnerzahl von bis zu 20000 auf. Entsprechend der Verteilung der Lebensmittelpunkte der Betroffenen zur Zeit der sexu- 
ellen Gewaltviktimisierungen ereignete sich das Kennenlernen zwischen Täterinnen bzw. Tätern und Betroffenen insgesamt betrachtet am häufigsten im Heim. In den Fällen von sexuellem Missbrauch außerhalb eines institutionellen Kontexts fand das Kennenlernen hingegen am häufigsten im kirchlichen Kontext (z. B. Gottesdienst oder Beichte) statt.

Insgesamt erlebten die Betroffenen mehrheitlich sexuellen Missbrauch durch eine einzelne Täterin bzw. einen einzelnen Täter. Jeweils rund jede bzw. jeder sechste Betroffene war multiplen Viktimisierungen durch mehrere Personen zeitgleich bzw. durch mehrere Personen zu unterschiedlichen Zeitpunkten ausgesetzt. Letztgenannte Täterkategorie fand sich vor allem bei Fällen sexuellen Missbrauchs, die sich in Heimen ereignet hatten. In Einklang mit vergleichbaren Befragungen handelte es sich in den meisten Fällen bei den Beschuldigten um Priester, Pfarrer oder Kapläne mit einem mittleren Alter von 43 Jahren. Entsprechend war ein Großteil der Täter männlich. Mehrheitlich waren die Täterinnen bzw. Täter den Familien der Betroffenen zumindest namentlich bekannt.

Die erfassten Taten erstreckten sich auf den Zeitraum von 1949 bis 1993, wobei der Anteil an Fällen, die sich im institutionellen Kontext ereignet hatten, in der vorliegenden Stichprobe seit den 1970er Jahren merklich zurückgegangen ist. Tatorte waren den Angaben der Betroffenen aus dem institutionellen Kontext zufolge erwartungsgemäß vor allem Heimund Internatsgebäude. Taten, die sich außerhalb eines institutionellen Kontexts ereignet hatten, geschahen überwiegend bei den Täterinnen bzw. Tätern Zuhause oder während Jugendfreizeiten bzw. Reisen. Die Anbahnung der (ersten) Tat wurde von den Betroffenen in der deutlichen Mehrheit als „hat das einfach getan“ beschrieben. Allerdings setzten die Täterinnen bzw. Täter in zwei bzw. drei von zehn Fällen Gewalt oder Drohungen ein. Mehr als zwei von zehn Betroffenen berichteten, die Täterinnen bzw. Täter hätten sie zu der ersten Tat verleitet.

Die konkreten Tathandlungen, welche den Betroffenen im Rahmen des sexuellen Missbrauchs widerfahren waren, erstreckten sich vom Stellen intimer Fragen zu ihrer Sexualität (in mehr als sieben von zehn Fällen) bis hin zur analen bzw. vaginalen Penetration (in mehr als drei von zehn Fällen). In der großen Mehrheit der Fälle handelte es sich bei den einzelnen Tathandlungen um wiederholte Viktimisierungen. Die Anzahl unterschiedlicher Missbrauchsformen sowie das Vorkommen der schwersten Viktimisierungen waren im institutionellen Kontext (und hier vor allem im Heimkontext) deutlich erhöht im Vergleich zu Taten, die sich außerhalb des institutionellen Kontexts ereigneten. Die Anzahl der unterschiedlichen 
Tathandlungen und die absoluten Tathäufigkeiten stiegen den Angaben der Betroffenen zufolge mit der Missbrauchsdauer.

Mehrheitlich waren die Betroffenen eigenen Angaben zufolge von den Täterinnen bzw. Tätern bedroht worden, damit sie nicht über die erlebte sexuelle Gewalt sprachen. Am häufigsten beinhalteten solche Drohungen „schlimme Konsequenzen“ für die Betroffenen und dass die Anschuldigungen nicht geglaubt würden.

Insgesamt erlebten mehr als zwei von zehn Betroffenen zusätzlich zur sexuellen Gewalt auch physische Gewalt durch die Täterin bzw. den Täter. Dies traf auf mehr als vier von zehn Betroffenen zu, die zum Zeitpunkt des Missbrauchs in einem institutionellen Kontext gelebt hatten. Wiederum waren Kinder und Jugendliche, die innerhalb eines Heimkontexts missbraucht worden waren, am stärksten von schwerer Gewalt betroffen. In mehr als drei von zehn Fällen wurde der sexuelle Missbrauch in eine religiöse Handlung (z. B. Beichte) eingebettet. Insgesamt berichtete die Mehrheit der Betroffenen von Zuwendungen durch die Täterinnen bzw. Täter oder Privilegien, die ihnen zuteil wurden. Am häufigsten handelte es sich dabei um besondere Aufmerksamkeit und Zuhören.

Der Konsum von Alkohol oder Drogen spielte den Angaben der Betroffenen zufolge im Rahmen des Missbrauchs in knapp drei von zehn Fällen eine Rolle. Mehrheitlich waren sich die befragten Betroffenen sicher, dass kein pornografisches Material von dem sexuellen Missbrauch angefertigt worden war, in mehr als zwei von zehn Fällen waren sich die Befragten diesbezüglich nicht sicher und in ungefähr jedem achten Fall wurden Fotos oder Videos von der sexuellen Viktimisierung erstellt.

Den Angaben der Betroffenen zufolge gab es in knapp acht von zehn Fällen bereits zum Zeitpunkt des Missbrauchs Personen, die davon Kenntnis hatten. Überwiegend handelte es sich dabei um andere Betroffene. Das Ende der sexuellen Gewaltviktimisierungen wurde mehrheitlich dadurch initiiert, dass die Betroffenen sich dem Einfluss der Täterin bzw. des Täters entweder aktiv oder passiv entzogen. In jedem achten Fall endete der Missbrauch dadurch, dass die Täterin bzw. der Täter versetzt wurde.

\section{III.2 Diskussion und Einordnung zentraler Ergebnisse}

In den vorangegangenen Abschnitten wurden vor allem die Ergebnisse des John Jay College (2004) und der österreichischen Befragung von LuegerSchuster (2012) zum Vergleich herangezogen, da es sich in beiden Fällen um Daten zum sexuellen Missbrauch durch katholische Geistliche handelt. 
Ergänzend wurde zudem auf eine Befragung des KFN zu sexuellem Missbrauch im Allgemeinen verwiesen (Stadler et al., 2012). Im Folgenden werden zentrale Ergebnisse dieses Kapitels aufgegriffen und über die bisher vorgenommenen Vergleiche hinaus mit anderen Arbeiten in Bezug gesetzt.

\section{Betroffenengeschlecht und institutioneller Kontext}

Augenfällig war beim direkten Vergleich der vorliegenden Ergebnisse mit den ausgewählten Befragungen vor allem die Überrepräsentation an Jungen unter den Betroffene sowie derjenigen Betroffenen, die zum Zeitpunkt des sexuellen Missbrauchs in einer Institution wie einem Heim oder einem Internat gelebt hatten. $\mathrm{Zu}$ berücksichtigen ist dabei, dass in der vorliegenden Stichprobe mehr männliche als weibliche Betroffene zur Zeit des Missbrauchs in einer solchen Institution gelebt hatten. Während im Allgemeinen Mädchen einem größeren Risiko ausgesetzt sind, sexuellen Missbrauch zu erleben (z. B. Finkelhor, 1994; Pereda et al., 2009; Stadler et al., 2012; Stoltenborgh, van IJzendoorn, Euser \& BakermansKranenburg, 2011), scheinen Jungen vor allem im institutionellen Kontext (z. B. Fitzpatrick et al., 2010; Hobbs, Hobbs \& Wynne, 1999) bzw. durch sexuellen Missbrauch im Rahmen der katholischen Kirche gefährdet zu sein (z. B. John Jay College, 2004; Lueger-Schuster, 2012).

Die Auswertung der bei der Anlaufstelle der Unabhängigen Beauftragten zur Aufarbeitung des sexuellen Kindesmissbrauchs eingegangenen Informationen ergab zum Beispiel ein ähnliches Bild (siehe Spröber et al., 2014): Betroffene, die dort das Erleben sexuellen Missbrauchs innerhalb eines institutionellen Kontexts geschildert hatten, waren zu 59.8 \% männlich. Spröber et al. begründen dieses Ungleichgewicht damit, dass in Deutschland generell mehr Jungen als Mädchen in Internaten und Heimen untergebracht sind und implizieren somit, dass der institutionelle Kontext und nicht das Geschlecht der Betroffenen ausschlaggebend für ein höheres Viktimisierungsrisiko ist. Dieser Logik folgend resultiert die höhere Missbrauchsprävalenz bei Jungen in institutionellen Kontexten daher, dass diese dort häufiger leben als Mädchen.

Inwiefern die höhere Prävalenz männlicher Betroffener von sexuellem Missbrauch durch katholische Geistliche dadurch bedingt ist, dass sie als Kinder häufiger in institutionellen Kontexten lebten bzw. leben, kann jedoch weder bei Spröber et al. (2014), noch anhand der vorliegenden Daten kausal geklärt werden. Festzuhalten ist, dass in der vorliegenden Befra- 
gung männliche Betroffene häufiger in einem institutionellen Kontext viktimisiert wurden und Mädchen eher außerhalb eines institutionellen Kontexts. In dieser Studie war von allen vier Möglichkeiten (1. weibliche Betroffene im institutionellen Kontext, 2. weibliche Betroffene im außerinstitutionellen Kontext, 3. männlicher Betroffener im institutionellen Kontext, 4. männlicher Betroffener im außerinstitutionellen Kontext) folglich der Fall am häufigsten, dass ein Junge innerhalb eines institutionellen Kontexts sexuelle Gewalt erlebt hatte. Allein aufgrund der vorliegenden Daten lässt sich an dieser Stelle nicht klären, ob mehr Jungen von sexuellem Missbrauch durch katholische Geistliche betroffen waren, weil diese häufiger in institutionellen Kontexten lebten (dann wäre der ausschlaggebende Faktor die Institution) oder ob die Prävalenz sexuellen Missbrauchs durch katholische Geistliche in institutionellen Kontexten erhöht war, weil dort mehr Jungen als Mädchen lebten (dann wäre der ausschlaggebende Faktor das Betroffenengeschlecht). Argumente lassen sich in der Literatur für beide Betrachtungsweisen finden.

Beispielsweise konnten Langevin, Curnoe und Bain (2000) in ihrer Studie anhand von phallometrischen Tests zeigen, dass sowohl bei männlichen Missbrauchstätern aus dem Kontext der katholischen Kirche als auch bei männlichen Missbrauchstätern außerhalb der katholischen Kirche mehrheitlich eine Präferenz für Jungen als Sexualpartner vorlag (siehe auch z. B. Firestone, Moulden \& Wexler, 2009; McGlone, 2003; Perillo, Mercado \& Terry, 2008; Sullivan, Beech, Craig \& Gannon, 2011). Wie bereits angedeutet, führte hingegen zum Beispiel Finkelhor (1984) vier Faktoren von sexuellen Straftaten an, die das Risiko sexuellen Missbrauchs in institutionellen Kontexten generell erhöhen können, da sich dort für die Täterinnen und Täter eher Gelegenheiten zum sexuellen Missbrauch ergeben und mit geringeren Widerstandskräften bei den Betroffenen $\mathrm{zu}$ rechnen ist (siehe auch z. B. Bundschuh, 2010; Helming et al., 2011).

Da sich sowohl Belege für das Geschlecht der Betroffenen als auch für den institutionellen Kontext als Risikofaktoren für das Erleben sexueller Gewalt im Kindes- oder Jugendalter finden lassen, liegt die Annahme nahe, dass beide Faktoren sich gegenseitig verstärken. Entsprechend kamen unter anderem Beyer, Higgins und Bromfield (2005) in ihrer Literaturübersicht zu dem Schluss, dass das Risiko sexuellen Missbrauchs für Mädchen im familiären Kontext höher ist, während der institutionelle Kontext besonders für Jungen ein hohes Viktimisierungsrisiko darstellt (siehe auch z. B. Beech, 1998): „Thus gender combined with environment may heighten risk of sexual abuse - in family or family-like environments, 
the risk was highest for girls; for boys, sexual assault was more common outside the familial context" (Beyer et al., 2005, S. 21). Diese Einschätzung deckt sich unter anderem mit den bei Fegert et al. (2011) berichteten Ergebnissen der Anlaufstelle der Unabhängigen Beauftragten zur Aufarbeitung des sexuellen Kindesmissbrauchs. Dort fanden sich „mehr Angaben zu Missbrauch von männlichen Betroffenen in Institutionen (...) als zu weiblichen Betroffenen“ (Fegert et al., 2011, S. 24). Demgegenüber dominierten bei den Berichten der weiblichen Betroffenen Schilderungen von innerfamiliärem Missbrauch (siehe auch z. B. Hobbs et al., 1999; Sullivan \& Beech, 2004).

Einsatz physischer Gewalt in Zusammenhang mit dem sexuellen Missbrauch

Ein weiteres zentrales Ergebnis betraf den Einsatz physischer Gewalt in Zusammenhang mit dem sexuellen Missbrauch. In ihrer deutschlandweiten Repräsentativbefragung zu sexuellem Missbrauch fragten Stadler et al. (2012) zwar nicht direkt nach zusätzlich von der Missbrauchstäterin bzw. dem Missbrauchstäter erlebter körperlicher Gewalt. Allerdings wurde das Einsetzen von Gewalt bei der Anbahnung der Tat erfasst. Insofern ist das dort berichtete Ergebnis von physischer Gewaltviktimisierung in rund einem Fünftel der Fälle (weibliche Betroffene: $19.9 \%$; männliche Betroffene: $17.5 \%$ ) als Untergrenze zu verstehen. In der vorliegenden Studie lag der Einsatz von Gewalt bei der Tatanbahnung mit $34.6 \%$ für weibliche und $26.0 \%$ für männliche Betroffene höher. Neben den unterschiedlichen Kontexten des sexuellen Missbrauchs sind bei diesem indirekten Vergleich wiederum die großen Unterschiede in der Zusammensetzung der Stichprobe (z. B. hinsichtlich des Alters und des Geschlechts der Befragten sowie der Samplingmethode) zu berücksichtigen.

Fasst man hingegen die Mehrfachantworten der Betroffenen auf die explizite Frage nach zusätzlicher körperlicher Gewalt durch die Täterin bzw. den Täter der vorliegenden Befragung zusammen (,hat mich geschlagen“, „hat mich getreten“, „,hat mich mit Gegenstand geschlagen“), erlebten fast jede fünfte weibliche Betroffene und jeder dritte männliche Betroffene in Zusammenhang mit der sexuellen Gewaltviktimisierung auch physische Gewalt durch die Täterin bzw. den Täter. Dieser Wert liegt im Vergleich mit den Ergebnissen der österreichischen Befragung deutlich niedriger: Lueger-Schuster (2012) berichtete, dass insgesamt $56 \%$ der Betroffenen 
sexuelle Gewalt in Kombination mit physischer (8\%) und psychischer Gewalt (48 \%) erlebt hatten (vgl. Firestone et al., 2009).

Im Rahmen der Auswertung der bei der Anlaufstelle der Unabhängigen Beauftragten zur Aufarbeitung des sexuellen Kindesmissbrauchs eingegangenen Informationen fanden Spröber et al. (2014), dass in mehr als vier von zehn Fällen zusätzlich bzw. in Zusammenhang mit dem sexuellen Missbrauch physische Gewalt gegen die Betroffenen ausgeübt worden war. Dabei traten keine Unterschiede in Abhängigkeit vom Kontext auf, in dem der Missbrauch den Angaben der Betroffenen zufolge stattgefunden hatte (römisch-katholischer Kontext: $45.8 \%$; protestantischer Kontext: $47.5 \%$; nicht-religiöser Kontext: $44.4 \%$ ). Zu berücksichtigen ist bei dem Vergleich der Daten von Spröber et al. mit den vorliegenden Ergebnissen, dass es sich dort ausschließlich um Fälle sexuellen Missbrauchs handelte, die sich in einem institutionellen Kontext ereignet hatten. Bei einer Betrachtung der Fälle, die sich den Angaben der Betroffenen der vorliegenden Studie zufolge in einem institutionellen Kontext ereignet hatten, ergaben sich ähnlich hohe Werte: $47.1 \%$ derjenigen Betroffene, die zum Zeitpunkt des sexuellen Missbrauchs in einer Institution wie einem Heim oder Internat gelebt hatten, berichteten von erlebter physischer Gewalt in $\mathrm{Zu}$ sammenhang mit der sexuellen Gewaltviktimisierung.

Dass in der vorliegenden Befragung männlichen Betroffenen häufiger als weiblichen eigenen Angaben zufolge zusätzlich körperliche Gewalt durch die Missbrauchstäterin bzw. den Missbrauchstäter widerfahren war, könnte darauf zurückzuführen sein, dass hier mehr Männer innerhalb eines institutionellen Kontexts missbraucht wurden und die Täterinnen bzw. Täter dort deutlich häufiger körperliche Gewalt gegen die Betroffenen einsetzten als Täterinnen bzw. Täter in nicht-institutionellen Kontexten. Ebenso fanden zum Beispiel Fitzpatrick et al. (2010) im Kontext institutionellen Missbrauchs hohe Korrelationen zwischen sexuellem Missbrauch und physischer Misshandlung. Als Erklärung für den vermehrten Einsatz von körperlicher Gewalt in institutionellen Kontexten konstatiert beispielsweise Müller-Hohagen (1994), dass die bis in die Siebzigerjahre des vergangenen Jahrhunderts hineinreichenden Erziehungsideologien ganz konkret Gewalthandlungen gegen Kinder begünstigten und legitimierten.

Innerkirchlicher vs. außerkirchlicher Missbrauch

Dass innerkirchliche Missbrauchstäter häufiger physische Gewalt einsetzten als Missbrauchstäter, die außerhalb eines kirchlichen Kontexts agier- 
ten, fanden beispielsweise Langevin et al. (2000). Dieser Befund leitet wiederum zu der Frage über, ob und gegebenenfalls inwiefern sich innerkirchlicher von außerkirchlichem Missbrauch unterscheidet. Generell ist hier anzumerken, dass unseres Wissens derzeit keine quantitativen Daten von Täterinnen bzw. Tätern und Betroffenen aus dem inner- vs. außerkirchlichen Bereich existieren, die einen direkten Vergleich ermöglichen würden. Fegert et al. (2011, S. 136) stellten beispielsweise hinsichtlich der Betroffenen fest, dass die „Stichprobe, die über Missbrauch im kirchlichen Kontext berichtete, (...) älter [ist] als diejenige, die von nicht-kirchlichen Kontexten berichtete". Dies deuteten die Autorinnen und Autoren als Hinweis darauf, dass „Missbrauchsfälle im kirchlichen Kontext objektiv seltener geworden sind" (Fegert et al., 2011, S. 136). Weiterhin wurden dort jedoch vor allem Vergleiche zwischen sexuellem Missbrauch im katholischen $v s$. evangelischen $v s$. nicht-kirchlichen institutionellen Kontext angestellt, die sich wiederum meist auf qualitative Daten und darüber hinaus auf Angaben der Kontaktpersonen von Betroffenen stützen.

Mit Blick auf die Täterinnen bzw. Täter fanden Haywood, Kravitz, Wasyliw, Goldberg und Cavanaugh (1996), dass eigene sexuelle Viktimisierungserfahrungen sowohl für klerikale als auch für nicht-klerikale Missbrauchstäter das Risiko einer Täterschaft erhöhten. Firestone et al. (2009) postulierten in diesem Zusammenhang, dass sich kirchliche von nicht-kirchlichen Missbrauchstäterinnen und -tätern qualitativ unterschieden: Sie wären tendenziell älter, gebildeter und den Vorschriften der katholischen Kirche entsprechend häufiger alleinstehend. Zudem berichteten Firestone et al., dass bei kirchlichen Missbrauchstätern antisoziale Persönlichkeitsstörungen mit einer geringeren Wahrscheinlichkeit vorlägen im Vergleich zu Missbrauchstätern im Allgemeinen. Diesbezüglich wiesen zum Beispiel Plante und Aldridge (2005) mithilfe des Minnesota Multiphasic Personality Inventory 2 (MMPI-2) bei Missbrauchstätern aus der katholischen Kirche im Vergleich zur Allgemeinbevölkerung höhere Werte hinsichtlich der Dimensionen Reizbarkeit und Ärger nach. Ebenso bezeichneten Perillo et al. (2008, S. 604) es als offensichtlich, dass sich die Gruppe der klerikalen Missbrauchstäter ,from the general abuser population in terms of basic background information such as education, IQ, and psychological history" unterscheidet.

Sullivan et al. (2011) verglichen in ihrer Studie wiederum Personen, die im beruflichen Kontext Kinder sexuell belästigt bzw. missbraucht hatten, mit inner- und außerfamiliären Missbrauchstätern. Die Autorinnen und Autoren fanden zwischen ,beruflichen“ und außerfamiliären Missbrauchstätern eher (aber nicht nur) Übereinstimmungen (z. B. hinsichtlich des Be- 
troffenengeschlechts und der Anzahl an Viktimisierungen), während zu innerfamiliären Tätern überwiegend Unterschiede bestanden. In dieser Studie handelte es sich in der ursprünglich rekrutierten Gruppe der ,beruflichen" Missbrauchstäter $(N=41)$ zu $66 \%$ um Täter aus einem kirchlichen Kontext. In einem Matching-Verfahren wurden jedoch nur $n=31$ Personen für die weiteren Analysen ausgewählt. Da Sullivan et al. nicht berichtet haben, wie hoch der Anteil der kirchlichen Missbrauchstäter in dieser reduzierten Stichprobe war, lassen sich keine weiteren Aussagen für diese Subgruppe ableiten. Demgegenüber wiesen beispielsweise Mercado, Tallon und Terry (2008) auf Ähnlichkeiten bei der Einteilung von Missbrauchstypen zwischen kirchlichen und nicht-kirchlichen Missbrauchstäterinnen bzw. -tätern hin.

Blanchard (1991, S. 244) hält die Unterschiede zwischen inner- und auBerkirchlichem sexuellen Missbrauch ebenfalls für vernachlässigbar: „Sexual relations with a parishioner is the exploitation of a power imbalance, a betrayal of trust, and is equivalent to abusing a family member. It differs little from incest". Im Gegensatz zu den bisher angeführten Positionen argumentiert Blanchard eher aus Perspektive der Betroffenen. Der innerfamiliäre und der innerkirchliche sexuelle Missbrauch wiesen insofern Ähnlichkeiten auf, als in beiden Fällen unter anderem ein Macht- und Vertrauensmissbrauch durch eine Person, die dem Kind intellektuell, körperlich und ,hierarchisch“ überlegen ist, vorläge. Terry und Tallon (2004, S. 40) führten hingegen die spirituellen Beeinträchtigungen als Besonderheit des sexuellen Missbrauchs durch katholische Geistliche an: „When an individual is victimized by a priest, they are not only harmed physically and emotionally, but spiritually as well“".

\section{III.3 Methodische Einschränkungen}

Sicherlich sind bei der Interpretation der im Rahmen unserer Befragung gewonnenen Daten methodische Limitationen zu berücksichtigen. Wie bereits erwähnt, handelt es sich bei der vorliegenden Stichprobe um eine selbstselektive, von Fegert et al. (2011) als „Inanspruchnahmepopulation“ bezeichnete Gruppe von Betroffenen (siehe auch z. B. Bundschuh, 2010). „Die Beschreibung einer spezifischen Inanspruchnahmepopulation stellt immer eine Selektion dar und der größte Selektionseffekt geht von der Motivation der Betroffenen aus, sich an die Anlaufstelle zu wenden“ (Fegert et al., 2011, S. 128). Mit Blick auf den Kontext, in dem sich der sexuelle Missbrauch ereignet hatte, fanden Fegert et al. beispielsweise, dass 
sich Betroffene, die sexuellen Missbrauch innerhalb eines institutionellen Kontexts erlebt hatten, häufiger schriftlich an die Anlaufstelle der Unabhängigen Beauftragten zur Aufarbeitung des sexuellen Kindesmissbrauchs wandten, während sich keine Unterschiede in der Häufigkeit von anrufenden $v s$. schreibenden Betroffenen zeigten, die innerfamiliärem Missbrauch ausgesetzt waren. Daraus lässt sich schlussfolgern, dass die Gruppe derjenigen Betroffenen, die in einem institutionellen Rahmen viktimisiert wurden, möglicherweise in der vorliegenden schriftlichen Befragung überrepräsentiert sind.

Darüber hinaus ist hinsichtlich der vorliegenden Studie - genau wie bei vergleichbaren Betroffenenbefragungen - zu bedenken, dass es sich um retrospektive Angaben zu hochbelastenden Ereignissen handelt, die unter Umständen fehlerbehaftet sind. Bei der Interpretation der Ergebnisse ist zudem zu berücksichtigen, dass Korrelationen nicht kausal interpretiert werden dürfen und die vorliegenden Befunde nicht auf ,alle Betroffenen von sexuellem Missbrauch durch katholische Geistliche" generalisiert werden sollten (siehe auch Hellmann \& Bartsch, 2014). In diesem Zusammenhang wiesen beispielsweise Fegert et al. (2011, S. 128) darauf hin, dass ihr methodisches Vorgehen bei der Datensammlung in Form von unstrukturierten Interviews wahrscheinlich ,automatisch zu einer Verzerrung im Sinne von schwerwiegenderen Fällen mit langzeitigen Folgen“" geführt hat. Denn dort konnten die Betroffenen frei von dem Erlebten erzählen bzw. darüber schreiben, ohne dass in irgendeiner Form Rückfragen gestellt wurden. In der vorliegenden Befragung wurde hingegen ein strukturiertes Erhebungsinstrument eingesetzt (siehe Fernau \& Hellmann, 2014; Kap. 3 in diesem Band), um dieser Verzerrung vorzubeugen.

Die angesprochenen Besonderheiten bei dem Rückgriff auf Inanspruchnahmestichproben bieten jedoch auch einige Vorteile. Fegert et al. (2011) betonten zum Beispiel, dass sich durch diese Form der Rekrutierung von Befragungsteilnehmerinnen und -teilnehmern im Gegensatz zur Verwendung von Repräsentativstichproben sicherstellen ließe, dass hinreichend große Fallzahlen für das betrachtete Phänomen erreicht werden könnten. In Repräsentativbefragungen sei dies häufig nicht der Fall bzw. nur anhand von enorm großen Ausgangsstichproben möglich. Daher eigneten sich Inanspruchnahmebefragungen für ,eine differenzierte Beschreibung von Typologien oder Phänomenologien“" (Fegert et al., 2011, S. 128) bei seltenen Viktimisierungsarten wie dem sexuellen Missbrauch durch katholische Geistliche häufig besser als umfassende Repräsentativbefragungen (vgl. Stadler et al., 2012). 
Zudem eigneten sich Inanspruchnahmestichproben vor allem dazu, Interventions- und Präventionsmaßnahmen für differenzierte Betroffenengruppen abzuleiten. Beispielsweise war aufgrund der Quotenstichprobenziehung (siehe Hellmann, 2014) die Gruppe der ehemaligen Heimkinder in der Repräsentativbefragung zu sexuellem Missbrauch bei Stadler et al. (2012) erheblich unterrepräsentiert. Daher ist davon auszugehen, dass dort eine deutliche Unterschätzung der Viktimisierung in Heimen vorliegt. „Wenn schon die Häufigkeit der Viktimisierung in Heimen als Folge der Samplingmethode in der aktuellen deutschen Repräsentativerhebung unterschätzt wird, so kann phänomenologisch über Missbrauch in Heimen aus dieser Stichprobe keine Aussage getroffen werden" (Fegert et al., 2011, S. 131). Allerdings ist in diesem Zusammenhang zu berücksichtigen, dass sich weder anhand der Ergebnisse der vorliegenden Befragung, noch anhand der Ergebnisse von Fegert et al. die tatsächliche Prävalenz von sexuellem Missbrauch (durch katholische Geistliche) im institutionellen Kontext abschätzen lässt. Dazu wäre die vollständige Kooperation der katholischen Kirche in Deutschland nötig gewesen (siehe Pfeiffer, Mößle \& Baier, 2014; Kap. 1 in diesem Band).

\section{Literatur}

Benkert, M. \& Doyle, T. P. (2009). Clericalism, religious duress and its psychological impact on victims of clergy sexual abuse. Pastoral Psychology, 58, 223-238.

Beech, A. R. (1998). A psychometric typology of child abusers. International Journal of Offender Therapy and Comparative Criminology, 42, 319-339.

Beyer, L. R., Higgins, D. \& Bromfield, L. (2005). Understanding organisational risk factors for child maltreatment: A review of literature. Melbourne: Australian Institute of Family Studies.

Blanchard, G. T. (1991). Sexually abusive clergymen: A conceptual framework for intervention and recovery. Pastoral Psychology, 39, 237-246.

Bortz, J. (2005). Statistik für Sozialwissenschaftler. Berlin: Springer.

Bundschuh, C. (2010). Sexualisierte Gewalt gegen Kinder in Institutionen. Nationaler und internationaler Forschungsstand. München: Deutsches Jugendinstitut.

Cohen J. (1988). Statistical power analysis for the behavioral sciences. Hillsdale, NJ: Erlbaum.

Egle, U. T. \& Abhary, S. G. (2005). Sexueller Missbrauch, Misshandlung, Vernachlässigung, Erkennung, Therapie und Prävention der Folgen früher Stresserfahrungen. Stuttgart: Schattauer.

Fegert, J., Rassenhofer, M., Schneider, T., Seitz, A., König, L. \& Spröber, N. (2011). Endbericht der wissenschaftlichen Begleitforschung zur Anlaufstelle der Unabhän- 
gigen Beauftragten zur Aufarbeitung des sexuellen Kindesmissbrauchs. Ulm: Universitätsklinikum Ulm.

Finkelhor, D. (1984). Child sexual abuse: New theory and research. New York, NY: Wiley.

Finkelhor, D. (1994). Current information on the scope and nature of child sexual abuse. The Future of Children, 4, 31-53.

Firestone, P., Moulden, H. M. \& Wexler, A. F. (2009). Clerics who commit sexual offenses: Offender, offense, and victim characteristics. Journal of Child Sexual Abuse, 18, 442-454.

Fitzpatrick, M., Carr, A., Dooley, B., Flanagan-Howard, R., Flanagan, E., Tierney, K., White, M., Daly, M., Shevlin, M. \& Egan, J. (2010). Profiles of adult survivors of severe sexual, physical and emotional institutional abuse in Ireland. Child Abuse Review, 19, 387-404.

Haywood, T. W., Kravitz, H. M., Wasyliw, O. E., Goldberg, J. \& Cavanaugh, J. L. (1996). Cycle of abuse and psychopathology in cleric and noncleric molesters of children and adolescents. Child Abuse and Neglect, 20, 1233-1243.

Hellmann, D. F. (2014). Repräsentativbefragung zu Viktimisierungserfahrungen in Deutschland - Forschungsbericht Nr. 122. Hannover: KFN.

Hellmann, D. F. \& Bartsch, T. (2014). Berücksichtigung der Belange von Betroffenen sexuellen Missbrauchs im Opferentschädigungsgesetz: Gleiches Recht für alle? Monatsschrift für Kriminologie und Strafrechtsreform, 97, 131-149.

Helming, E., Kindler, H., Langmeyer, A., Mayer, M., Entleitner, C., Mosser, P. \& Wolff, M. (2011). Sexuelle Gewalt gegen Mädchen und Jungen in Institutionen Rohdatenbericht. München: Deutsches Jugendinstitut.

Hobbs, G. F., Hobbs, C. J. \& Wynne, J. M. (1999). Abuse of children in foster and residential care. Child Abuse and Neglect, 23, 1239-1252.

John Jay College (2004). The nature and scope of sexual abuse of minors by Catholic priests and deacons in the United States, 1950-2002. Washington, DC: United States Conference of Catholic Bishops (USCCB).

Langevin, R., Curnoe, S. \& Bain, J. (2000). A study of clerics who commit sexual offenses: Are they different from other sex offenders? Child Abuse and Neglect, 24, 535-545.

Lueger-Schuster, B. (2012). Psychotraumatologische Fragestellungen zu Gewalt und Missbrauch in der Katholischen Kirche. Wien: Universität Wien.

MacLean, K. (2003). The impact of institutionalization on child development. Development and Psychopathology, 15, 853-884.

McGlone, G. J. (2003). Prevalence and incidence of Roman Catholic clerical sex offenders. Sexual Addiction and Compulsivity: The Journal of Treatment and Prevention, 10, 111-121.

Mercado, C. C., Tallon, J. A. \& Terry, K. J. (2008). Persistent sexual abusers in the Catholic church: An examination of characteristics and offense patterns. Criminal Justice and Behavior, 35, 629-642. 
Müller-Hohhagen, J. (1994). Geschichte in uns. Psychogramme aus dem Alltag. München: Knesebeck.

Pereda, N., Guilera, G., Forns, M. \& Gómez-Benito, J. (2009). The international epidemiology of child sexual abuse: A continuation of Finkelhor (1994). Child Abuse and Neglect, 33, 331-342.

Perillo, A. D., Mercado, C. C. \& Terry, K. J. (2008). Repeat offending, victim gender, and extent of victim relationship in Catholic church sexual abusers: Implications for risk assessment. Criminal Justice and Behavior, 35, 600-614.

Plante, T. G. (1996). Catholic priests who sexually abuse minors: Why do we hear so much yet know so little? Pastoral Psychology, 44, 305-310.

Plante, T. G. \& Aldridge, A. (2005). Psychological patterns among Roman Catholic clergy accused of sexual misconduct. Pastoral Psychology, 54, 73-80.

Spröber, N., Schneider, T., Rassenhofer, M., Seitz, A., Liebhardt, H., König, L. \& Fegert, J. M. (2014). Child sexual abuse in religiously affiliated and secular institutions: A retrospective descriptive analysis of data provided by victims in a government-sponsored reappraisal program in Germany. BMC public health, 14, 282.

Stadler, L., Bieneck, S. \& Pfeiffer, C. (2012). Repräsentativbefragung sexueller Missbrauch-Forschungsbericht Nr. 118. Hannover: KFN.

Stoltenborgh, M., van IJzendoorn, M. H., Euser, E. M. \& Bakermans-Kranenburg, M. J. (2011). A global perspective on child sexual abuse: Meta-analysis of prevalence around the world. Child Maltreatment, 16, 79-101.

Sullivan, J. \& Beech, A. (2004). A comparative study of demographic data relating to intra-and extra-familial child sexual abusers and professional perpetrators. Journal of Sexual Aggression, 10, 39-50.

Sullivan, J., Beech, A. R., Craig, L. A. \& Gannon, T. A. (2011). Comparing intrafamilial and extra-familial child sexual abusers with professionals who have sexually abused children with whom they work. International Journal of Offender Therapy and Comparative Criminology, 55, 56-74.

Terry, K. J., Smith, M. L., Schuth, K., Kelly, J. R., Vollman, B. \& Massey, C. (2011). The causes and context of sexual abuse of minors by Catholic priests in the United States, 1950-2010. Washington, DC: United States Conference of Catholic Bishops (USCCB).

Terry, K. J. \& Tallon, J. (2004). Child sexual abuse: A review of the literature. New York, NY: John Jay College.

Wetzels, P. (1997). Gewalterfahrungen in der Kindheit: Sexueller Mißbrauch, körperliche Mißhandlung und deren langfristige Konsequenzen. Baden-Baden: Nomos.

Youngleson, M. L. (1973). The need to affiliate and self-esteem in institutionalized children. Journal of Personality and Social Psychology, 26, 280-286. 